\title{
A influência da Operação Mãos Dadas na imagem institucional da Polícia Militar de Santa Catarina
}

The influence of Operation Hands Held on THE INSTITUTIONAL IMAGE OF THE SANTA CATARINA Military Police

\section{LA INFLUENCLA DE LA OPERACIÓN MANOS DADAS EN la imagen institucional de la Policía Militar DE SANTA CATARINA}

Submetido em 03 de janeiro de 2020.

Aceito em 20 de maio de 2021

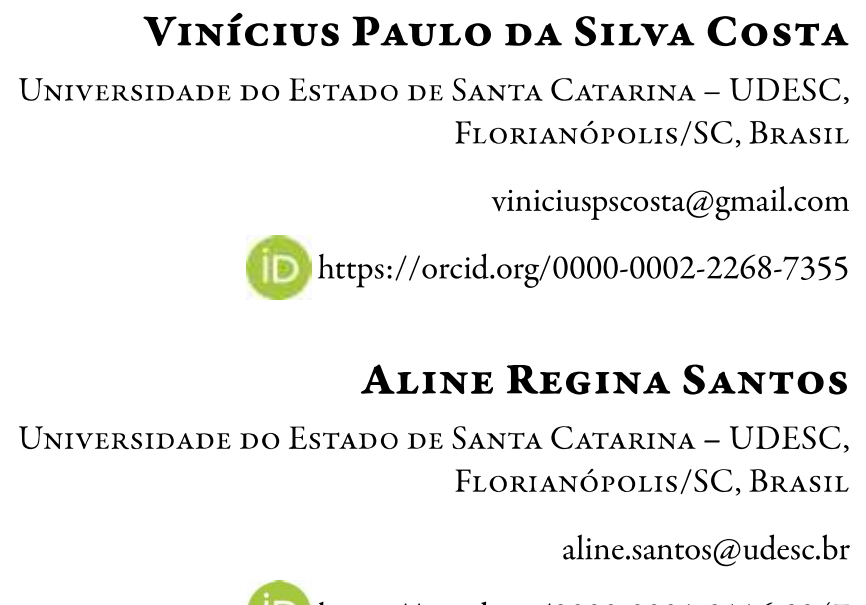

iD https://orcid.org/0000-0001-9116-9247

Juliane Pierri Ardigo

Universidade do Estado de Santa Catarina - UDESC,

Florianópolis/SC, BRASIL

juh.pierri@gmail.com

iD https://orcid.org/0000-0001-8113-7313

\section{RESUMO}

As pesquisas de imagem em organizações públicas têm aumentado de frequência em anos recentes, devido a percepção de que uma boa imagem exerce influência na reputa- 
ção de uma organização perante seu público-alvo. No setor público, pesquisas de imagem contribuem para tomada de decisão, principalmente no que tange à comunicação, beneficiando os cidadãos que utilizam os serviços prestados. Nesse sentido, o objetivo deste estudo foi analisar a imagem da Polícia Militar de Santa Catarina (PMSC) na comunidade Vila União, após a introdução da Operação Mãos Dadas (OMD). A pesquisa desenvolvida possui caráter exploratório, qualitativo e quantitativo. A coleta de dados quantitativos foi realizada pela aplicação de um questionário survey em uma amostra de moradores da Vila União. Os resultados mostram que o impacto da operação na imagem percebida da PMSC pelos moradores da região foi positivo, visto que houve indicação de melhora na avaliação de quatro critérios (segurança da comunidade, qualidade de vida, convivência com a PMSC e confiança da PMSC), depois da implementação da OMD.

Palavras-Chave: imagem corporativa; Polícia Militar; reputação institucional; credibilidade institucional; percepção de segurança.

\section{ABSTRACT}

Researches about public organizations' image are increasing in recent years due to the perception that a good image can influence the organization's reputation to its stakeholders. In the public field, image studies contribute to the organization's decision-making process, mainly regarding communication aspects, benefiting those citizens that are public service users. In this regard, this study aims to analyze the PMSC's image among the Vila União community after they introduced the "Operation Hands Held". This research is exploratory, qualitative and quantitative. The quantitative data gathering was done through a survey with a sample from the Vila União community. The results show that the operation had a positive impact in the perceived image of the PMSC by inhabitants of the community, since they indicated that the current situation, after the $\mathrm{OHH}$ was implemented, is better when analyzing four variables (community safety, quality of life, coexistence with PMSC and trust in PMSC).

KeYwords: corporate image; Military Police; institutional reputation; institutional credibility; security perception.

\section{RESUMEN}

Las pesquisas de imagen sobre las organizaciones públicas están aumentando en los últimos años debido a la percepción de que una buena imagen puede influir en la reputación de la organización ante sus grupos de interés. En el ámbito público, los estudios de imagen contribuyen a la toma de decisiones de la organización, principalmente en los aspectos comunicativos, beneficiando a los ciudadanos que son usuarios de los servicios públicos. En este sentido, este estudio tiene como objetivo analizar la imagen de la PMSC en la comunidad de Vila União después de que se inició la “Operación Manos Dadas”. Esta inves- 
tigación es exploratoria, cualitativa y cuantitativa. La recolección de datos cuantitativos se realizó a través de una encuesta con una muestra de la comunidad de Vila União. Los resultados muestran que la operación tuvo un impacto positivo en la imagen percibida de la PMSC por los habitantes de la comunidad, ya que indicaron una mejor evaluación de cuatro criterios (seguridad comunitaria, calidad de vida, convivencia con la PMSC y confianza en la PMSC) después de la implementación de la OMD.

Palabras ClaVe: imagen corporativa; Policía Militar; reputación institucional; credibilidad institucional; percepción de seguridad.

\section{INTRODUÇÃo}

Pesquisas de imagem são comumente usadas em organizações de caráter privado, porém sua aplicação não é restrita a esse grupo, portanto podem ser aplicadas a outros setores (SCHULER; TONI, 2015). A ampla utilização de tais pesquisas no meio empresarial está relacionada com o fato de que se considera a imagem corporativa como um recurso estratégico capaz de melhorar o posicionamento da organização por meio da melhoria de desempenho (GOMES; SAPIRO, 1993). A gestão da imagem corporativa é uma forma de atrair os stakeholders, sendo um recurso necessário em um cenário de alta competitividade $(\mathrm{BARICH}$; KOTLER, 1991 apud GOMES; SAPIRO, 1993).

Gomes e Sapiro (1993) afirmam que os clientes em potencial possuem uma imagem mental acerca da organização, seja essa referente ao fornecedor como um todo ou a qualidade de seus produtos e serviços, bem como de outras facetas do negócio. De acordo com os autores, a empresa que consegue obter uma boa imagem colhe resultados positivos em diversos campos, tais quais a gestão de talentos e fidelização dos consumidores. Portanto, independente do tamanho de uma empresa, investir numa boa imagem torna-se uma vantagem competitiva. Corroborando com isso, Lamons (1992 apud GOMES; SAPIRO, 1993) aponta que a gestão da imagem corporativa contribui para que a organização obtenha uma reputação favorável junto ao mercado, de forma que a empresa colha os resultados positivos com a obtenção de lucros crescentes e alta participação no mercado.

A formação da imagem institucional é um processo considerado multidimensional (SANTOS et al., 2019), no qual participam 
as crenças, experiências, valores e personalidade de cada indivíduo (GOMES; SAPIRO, 1993). Conforme apontado por Gomes e Sapiro (1993), as crenças podem influenciar a imagem que um indivíduo tem de uma corporação de forma distorcida e estereotipada. Ao mesmo tempo em que as crenças podem ter um papel negativo na formação mental de uma imagem corporativa, elas podem determinar a confiabilidade das marcas e das organizações, conforme apontado pelos autores. Tal fato evidencia a necessidade de uma organização alcançar um posicionamento favorável de sua imagem em relação às crenças de seu público-alvo.

Ainda que a temática "imagem corporativa" esteja fortemente relacionada com o meio empresarial, esse assunto está ganhando corpo no âmbito das organizações públicas. A prática de pesquisa de marketing de imagem voltada ao setor público é relevante no sentido de melhorar o relacionamento dessas instituições com o cidadão. Nesse sentido, a organização deve estar disposta a promover mudanças de atitudes, comportamentos, procedimentos e hábitos, principalmente os referente aos procedimentos de comunicação interna e externa, a fim de se beneficiar dos resultados da pesquisa.

Dentre as publicações acadêmicas recentes que abordam o tema de imagem corporativa no setor público está o trabalho de Souza (2016), que teve como objeto de pesquisa a análise do entendimento sobre o Tribunal de Contas segundo a visão dos cidadãos de Curitiba. Outra publicação sobre a mesma temática é o de Santos et al. (2017), no qual os autores buscaram descobrir a percepção da imagem das ouvidorias públicas de Florianópolis pelos seus cidadãos.

Considerando a relevância da temática "imagem institucional" para organizações públicas, o presente trabalho tem como objetivo analisar a imagem da Polícia Militar de Santa Catarina (PMSC) no conjunto habitacional Vila União após a introdução da "Operação Mãos Dadas” (OMD), sob a ótica do marketing institucional. A temática imagem corporativa associada à Polícia Militar mostra-se relevante, uma vez que a atividade policial, segundo Silva (2020, p. 125), é muitas vezes vista como uma "ação repressiva e sancionadora frente aos desarranjos sociais que brotam da sociedade". Para o autor

"Essa visão deturpada sobre a atividade policial, que a tem 
como uma função estatal meramente reativa já não tem mais razão de ser nos tempos atuais, uma vez que decorre de um modelo obsoleto de segurança pública que já não condiz com a arquitetura funcional que as constituições democráticas deram às polícias." (SILVA, 2020, p. 125)

Consoante com a abordagem desta pesquisa, Silva (2020) propõe que a atividade policial adote uma postura de gestão de conflitos presentes nas comunidades - assim como feito na Operação Mãos Dadas, analisada nesta pesquisa. Assim, para alcançar o objetivo proposto, se fez necessário: identificar a confiança da comunidade Vila União na PMSC antes e depois da OMD, verificar o conhecimento da comunidade sobre a OMD e identificar associações de palavras com a operação e com a PMSC.

A Polícia Militar é uma organização pública que visa manter a ordem e a segurança dos cidadãos. Ainda assim, conforme Loader (1999), a partir da inversão de poderes na cultura do consumo, estando este nas mãos dos consumidores, emerge uma discussão acerca da “mercantilização da polícia”. Tal fato tem implicações na organização interna desta instituição, como a adoção de termos de mercado na estrutura interna, bem como no posicionamento frente ao mercado emergente de segurança privada.

Loader (1999) aponta que existem três principais desdobramentos da mercantilização da polícia pública. $\mathrm{O}$ primeiro se refere à transformação da gestão para um formato mais parecido com o dos negócios. $\mathrm{O}$ segundo está relacionado com o consumismo no qual a sociedade está imersa. Nesse sentido, o público que é atendido pelos serviços prestados pela segurança pública, passa a ser visto como um consumidor. É interessante que essa nova orientação, ancorada na lógica do consumo, sugere a adoção de consultas públicas aos cidadãos e utilização de pesquisas de satisfação com o objetivo de compreender melhor as necessidades da população em relação à polícia, bem como para saber o que as pessoas pensam da instituição - ou seja, a imagem e reputação corporativa. Por fim, o terceiro desdobramento da mercantilização da polícia se refere ao gerenciamento e promoção de sua imagem através de canais e de departamentos de relações públicas próprios com profissionais capacitados para atuar na comunicação. 
A OMD é caracterizada por associar ações preventivas e de intervenção social a fim de levar o bem-estar social para comunidades com alto índice de criminalidade associado à atuação de facções criminosas, buscando agir de maneira preventiva para a redução desses índices (MACHADO, 2018). A Prefeitura Municipal de Florianópolis (PMF) classificou a região como uma área de interesse social (FLORIANÓPOLIS, 2006). A Vila União foi criada, por iniciativa da PMF, a partir da junção de comunidades rivais entre si, sendo, desde sua gênese, um local de disputas de facções relacionadas com o narcotráfico (SILVA, 2010). A composição do conjunto habitacional combinada com os problemas sociais enfrentados pela comunidade levou à intervenção da PMSC através da OMD.

Conforme já mencionado, percebe-se o aumento no número de estudos de imagem no setor público (SANTOS et al., 2019). A publicação mais recente encontrada pelos autores que relaciona a pesquisa de imagem com o setor público foi um estudo de Santos et al. (2019), que estudou a imagem percebida pelos moradores da Grande Florianópolis sobre a Polícia Militar de Santa Catarina. Além deste, outros estudos relacionados a essa temática são os relatórios de estágio produzidos no Grupo de Estudos e Pesquisa em Marketing (GEPEM) do Centro de Ciências da Administração e Socioeconômicas (ESAG) da Universidade do Estado de Santa Catarina (UDESC), a exemplo de Pessoa (2017), Silva (2017) e Laurindo (2018), cujos relatórios estão relacionados com a imagem da PMSC. Portanto, este trabalho pretende somar-se às produções já existentes e servir de subsídio para que os agentes públicos envolvidos no objeto estudado possam melhorar suas políticas direcionadas à sociedade.

\section{IMAGEM INSTITUCIONAL}

Imagem organizacional ou corporativa são sinônimos de imagem institucional. Adicionalmente, seu conceito é apresentado de maneira diferente pelos autores, não havendo um consenso na literatura científica com respeito a definição do termo (SCHULER; TONI, 2015). Dentre os conceitos encontrados e analisados, destacam-se o da multidimensionalidade da imagem, que denota a dificuldade de traduzir a imagem percebida de uma organização em apenas um fator; e 
a definição de que a imagem corporativa é um conceito mental sobre uma instituição (DOWLING, 1986 apud SANTOS et al., 2019).

O fato de as imagens corporativas serem impressões ou percepções mentais de seus públicos, implica a necessidade de realização de pesquisa de imagem por parte das organizações que almejam uma boa reputação frente aos seus stakeholders, conforme afirmam Schuler e Toni (2015). Corroborando com isso, Tran et al. (2015) afirmam que a imagem corporativa positiva é vista pelas instituições como uma forma de ganhar a confiança de seus stakeholders, algo especialmente importante em ambientes competitivos.

Tran et al. (2015) elaboraram um modelo conceitual do processo de formação de imagem corporativa, no qual sete dimensões interagem com a personalidade e a comunicação corporativa, a fim de criar a imagem institucional. Esta, traduz as sete dimensões em variáveis da imagem corporativa. As sete dimensões são: aparência física, sentimentos positivos, ambiente, aparência online, aparência dos empregados, comunicações externas e, por fim, atitude e comportamento. A imagem corporativa traduz essas sete dimensões em cinco variáveis: conscientização, familiaridade, favorabilidade, confiança e advoca$c y$ (tradução livre: apoio dado). Essas variáveis representam os níveis de profundidade da imagem institucional na mente dos stakeholders. Destaca-se que o mais alto nível corresponde ao advocacy, que ocorre quando a confiança na organização é tão grande que os stakeholders a defendem e apoiam. Além de propor o modelo, os autores afirmam que o processo de formação da imagem corporativa é similar ao processo de formação da reputação organizacional, demonstrando que existe uma relação entre essas duas características.

É evidente que uma boa imagem organizacional traz bons resultados para a empresa. Nesse sentido, as pesquisas de imagem buscam verificar a percepção da imagem institucional por parte dos stakeholders de uma organização. $\mathrm{O}$ resultado da pesquisa classifica a percepção da imagem como positiva ou negativa e, a partir deste, a instituição pode traçar novas estratégias para alcançar seus propósitos (SCHULER; TONI, 2015). 


\section{Reputação e Confiança}

Como evidenciado no tópico anterior, a imagem organizacional está relacionada com a reputação corporativa. Nesse sentido, conforme Chun (2005), o termo reputação corporativa também sofre com paradigmas de definição de constructo, ou seja, é abordado e conceituado de diferentes formas por diferentes autores. A autora define o termo como a síntese das percepções que os stakeholders de uma organização tem sobre ela. Para Chun (2005), a imagem corporativa é constituída de três elementos-chave: a imagem institucional, a identidade organizacional atual e a desejada.

É importante ressaltar que, ainda que estejam relacionados, a imagem organizacional é diferente da reputação corporativa. Enquanto a imagem é considerada uma crença ou percepção recente sobre uma organização, independentemente de experiência com ela vivida, a reputação é uma percepção que tem bases sólidas e profundas, pois é derivada desta experiência (CHUN, 2005). É digno de nota que os conceitos de imagem e reputação são inter-relacionados, de forma que a alteração em uma dessas dimensões é capaz de modificar a percepção dos stakeholders da outra (TRAN et al., 2015). De acordo com Chun (2005), a imagem é uma dimensão organizacional que pode ser mais facilmente modificada através da comunicação com os públicos de interesse, ao passo que a reputação exige um esforço contínuo e consistente para que ocorra a mudança de percepção, visto que deriva de um julgamento de valor sobre a organização baseado em suas ações ao longo do tempo.

Ferreira e Luiz (2016) identificaram, a partir de uma revisão de literatura, dez componentes da reputação corporativa: autenticidade, sinceridade, credibilidade, transparência, qualidade, distintividade, consistência, visibilidade, confiabilidade e responsabilidade. Tais variáveis foram utilizadas para a elaboração de um índice de reputação corporativa que, a partir de testes estatísticos, concluiu que seis fatores são essenciais para a mensuração da reputação, a saber: responsabilidade e confiança; reconhecimento; transparência; qualidade; coerência; e credibilidade. Os fatores que explicam o índice da reputação corporativa corroboram com a explicação apresentada anteriormente sobre a experiência necessária para estabelecer a reputação. 
É relevante o fato de que a confiança na organização é apontada como importante tanto para a reputação quanto para a imagem corporativa (GOMES; SAPIRO, 1993; FERREIRA; LUIZ, 2016). Gomes e Sapiro (1993) utilizam o conceito da teoria dos jogos com o intuito de ilustrar a importância da consistência das ações, por parte das organizações, na construção da sua credibilidade, de modo que a confiança afeta a reputação percebida e indica as ações futuras, impactando na imagem institucional. Tran et al. (2015) descrevem que a confiança em uma organização reflete nos sentimentos positivos em relação a ela. Tais sentimentos fazem parte dos elementos de expressão visual que compõe o processo de formação da imagem corporativa.

\section{IMAgem Corporativa, Reputação e Confiança no Setor Público}

Foi realizado para este estudo um levantamento bibliográfico com o objetivo de verificar a existência de publicações sobre imagem, reputação e confiança corporativa no setor público. Foram selecionados para análise treze artigos sobre o setor público que abordam os constructos já mencionados, cujos títulos e autores podem ser observados no no Quadro 1. Dentre os artigos selecionados, sete se referem à imagem institucional, quatro à reputação corporativa e dois à confiança. Cabe ressaltar que, como apontado anteriormente, esses constructos são inter-relacionados, de modo que os artigos foram classificados de acordo com utilização dos termos nas palavras-chave, título ou resumo.

Quadro 1 - Artigos envolvendo imagem, reputação e confiança corporativa

\begin{tabular}{|c|c|}
\hline Tema analisado & Autores (ano) \\
\hline \multirow{4}{*}{ Imagem } & VIEIRA; FREITAS (2007) \\
\cline { 2 - 2 } & NUNES et al. (2008) \\
\cline { 2 - 2 } & SAUERBRONN; LODI (2012) \\
\cline { 2 - 2 } & SILVA et al. (2017) \\
\cline { 2 - 2 } & BARROS; MARTINS (2017) \\
\cline { 2 - 2 } Reputação & SANTOS et al. (2017) \\
\cline { 2 - 2 } & SANTOS et al. (2019) \\
\cline { 2 - 2 } & DALMONECH et al. (2016) \\
\cline { 2 - 2 } & FERREIRA; LUIZ (2016) \\
\cline { 2 - 2 } & RAMALHO; RESENDE (2016) \\
\hline \multirow{4}{*}{} & SOUZA (2016) \\
\hline
\end{tabular}




\begin{tabular}{|c|c|}
\hline \multirow{2}{*}{ Confiança } & ZANINI et al. (2013) \\
\cline { 2 - 2 } & SILVA; RIBEIRO (2016) \\
\hline
\end{tabular}

Fonte: os autores (2020).

Percebe-se uma preferência por abordagens quantitativas com emprego de coleta de dados através de questionários tipo survey, no entanto, metodologias qualitativas, como entrevistas em profundidade, também foram utilizadas em alguns artigos analisados.

O presente trabalho apresenta maior convergência com os artigos listados na categoria imagem institucional. Destaca-se a convergência deste com o artigo publicado por Barros e Martins (2017), que avalia os impactos do Parlamento Jovem Brasileiro na imagem do Poder Legislativo de acordo com a perspectiva de seus egressos. A similaridade tange ao aspecto de avaliação de imagem antes e depois da experiência com a organização analisada. Já o estudo de Santos et al. (2017) buscou analisar a imagem das ouvidorias públicas na percepção dos cidadãos de Florianópolis, bem como o nível de conhecimento das pessoas acerca desses órgãos públicos. Ao passo que o artigo de Santos et al. (2019) foi um estudo de imagem sobre a PMSC na perspectiva de moradores da Grande Florianópolis. Os dois últimos estudos foram desenvolvidos com a participação de membros do Grupo de Estudos e Pesquisas de Marketing (GEPEM) da UDESC, assim como o presente trabalho.

Os demais artigos, ainda que utilizem constructos de imagem corporativa, tiveram diferenças significativas em relação a abordagem e metodologia empregada no estudo em pauta. Vieira e Freitas (2007) conduziram um estudo no Banco Central a fim de compreender a relação entre transparência e imagem institucional e concluíram que a transparência influencia na imagem percebida, pois existe um círculo vicioso entre reputação, imagem e credibilidade. Já Nunes et al. (2008) buscaram analisar os motivos da busca de emprego no setor público em empresas de energia. Dentre os achados de sua pesquisa, está o apontamento de que a "imagem da empresa" foi uma motivação para ingressar na carreira, o que demonstra a importância da gestão da imagem institucional como forma de atrair mão de obra nesse setor. No caso do estudo de Sauerbronn e Lodi (2012), foi utilizada a análise do discurso publicitário nas peças lançadas pelo Conselho Nacional de Justiça a fim de determinar a imagem institucional do Poder Judiciá- 
rio. Conforme os autores, a utilização de campanhas publicitárias pelo Judiciário já denota uma mudança de comportamento, de ator passivo para ativo. Ademais, foram identificadas duas categorias de discurso publicitário nas peças analisadas: discussão de questões sociais e discurso operacional. Por fim, Silva et al. (2017) mostraram a importância de um planejamento estratégico numa central de abastecimento farmacêutico, ressaltando que a gestão pública gera expectativa por parte dos que usufruem seus serviços e podem resultar em satisfação, neutralidade ou frustração, impactando sua imagem.

No que tange aos estudos relacionados com o constructo de reputação corporativa, destaca-se o de Ferreira e Luiz (2016) que construíram um índice capaz de medir a reputação corporativa de uma instituição de ensino superior pública. A escala de mensuração construída por eles considera a influência de seis fatores na reputação corporativa: responsabilidade e confiança; reconhecimento; transparência; qualidade; coerência; e credibilidade. Na mesma direção, Dalmonech et al. (2016) conduziram um estudo em uma instituição pública de ensino, mas seu objetivo foi avaliar os fatores que influenciam no marketing boca a boca. Nesse sentido, os autores investigaram se a reputação institucional influenciava na indicação dos alunos. Em conclusão, demonstrou-se a importância da satisfação e do comportamento da ação do marketing boca-a-boca para que exista a indicação da instituição de ensino. No caso do estudo de Ramalho e Resende (2016), foi investigada a reputação da empresa de transporte público de Belo Horizonte na visão de motoristas de veículos particulares e taxistas através da aplicação de um questionário baseado no modelo teórico Rep Track Pulse do Reputation Institute. $\mathrm{O}$ modelo avalia sete dimensões da reputação: desempenho; produtos e serviços; inovação; ambiente de trabalho; governança; cidadania; e liderança. Conforme os autores, o resultado foi a constatação de uma percepção desfavorável em relação às dimensões. Já o estudo de Souza (2016) buscou compreender a perspectiva dos cidadãos de Curitiba sobre o entendimento do órgão público Tribunal de Contas. $\mathrm{O}$ autor utilizou a análise de conteúdo para categorizar e agrupar os resultados e concluiu que o órgão é visto como um órgão fiscalizador pela maioria, além disso, há um desconhecimento generalizado acerca de suas atribuições.

Os estudos referentes à confiança nas organizações selecionados foram dois, o primeiro, realizado por Silva e Ribeiro (2016), tinha por objetivo analisar a confiança nas instituições democráticas com base em experiências traumáticas. Os autores apontaram que existe a 
perda de confiança nas instituições com base na vitimização por crime, com consequente efeito de contaminação em outras instituições públicas, na visão dos cidadãos. A segunda pesquisa, realizada por $\mathrm{Za}$ nini et al. (2013), investigou elementos em gestão de equipes de alto desempenho e identificou que a confiança pode ser um elemento de coordenação informal, quando se trata da efetividade operacional em equipes de trabalho, especificamente em uma unidade policial de operações especiais do Rio de Janeiro, o BOPE. Este último estudo difere do anterior visto que a indicação de confiança está relacionada a um público-alvo interno, da organização e não ao público externo. Além desses, Barros e Martins (2017), já mencionados no constructo de imagem, também concluíram que o conhecimento acerca de uma organização é capaz de influenciar a confiança nela.

\section{Percurso Metodológico}

A pesquisa realizada teve caráter exploratório-descritivo, tal classificação se justifica com o objetivo de expor o fenômeno em estudo (MATTAR, 2005). A etapa inicial define-se como exploratória, mediante realização de pesquisa bibliográfica e entrevista em profundidade. A etapa descritiva fez uso de pesquisa quantitativa, com uso de questionário do tipo survey para coleta de dados (MALHOTRA, 2012). Para fins de apresentação, a pesquisa foi dividida em duas etapas - exploratória e descritiva - as quais são apresentadas a seguir.

\subsection{ETAPA EXPLORATória}

Além da pesquisa bibliográfica de trabalhos relacionados com a temática de investigação, essa etapa consistiu na elaboração e aplicação de um roteiro semiestruturado de entrevista em profundidade. O objetivo foi o levantamento de informações que pudessem auxiliar no desenvolvimento do questionário aplicado na etapa quantitativa. Neste estudo, foi realizada uma entrevista em profundidade com o presidente da Associação de Moradores da Vila União.

Para a entrevista semiestruturada foi utilizado um gravador de voz em conjunto com o aplicativo reconhecedor de falas Speechnotes, 
com a finalidade de auxiliar na transcrição da entrevista. Após a transcrição, foi utilizada a análise interpretativa como ferramenta de análise de dados qualitativos (SEVERINO, 2007).

\subsection{ETAPA Descritiva}

A partir das informações obtidas na etapa exploratória da pesquisa, elaborou-se um instrumento de coleta de dados em formato de questionário do tipo survey. Malhotra (2012) explica que o método de aplicação de questionários permite a análise e interpretação dos dados de uma maneira mais simples, considerando-se que muitas perguntas têm respostas fechadas (múltipla escolha). No instrumento de coleta de dados utilizado nesta pesquisa, as perguntas de múltipla escolha são preponderantes em relação aos demais tipos de pergunta. Os blocos de informações que compõem os questionário são: Perfil demográfico; Principais associações de palavras com a Operação Mãos Dadas e com a Polícia Militar de Santa Catarina; Importância da Operação Mãos Dadas e Polícia Militar para a comunidade da Vila União e confiança na PM atualmente; Avaliação da Operação Mãos Dadas e atuação da PMSC; e, por fim, a Vila União antes e depois da Operação Mãos Dadas.

Cabe ressaltar que as perguntas acerca da confiança e da importância da PMSC, bem como a da importância da OMD, ofereciam uma escala de zero a dez como possibilidade de resposta, sendo dez a mais positiva. Ao passo que as percepções dos moradores sobre a segurança, qualidade de vida, confiança na PMSC e convivência com a PMSC antes e depois da implementação da Operação Mãos Dadas, bem como a avaliação das atividades da OMD e da atuação da PMSC na OMD, ofereciam uma escala do tipo Likert de cinco pontos como possibilidade de resposta (de muito ruim até muito bom), além da possibilidade de assinalar a opção "não sei opinar".

De acordo com a Prefeitura Municipal de Florianópolis (2006), o universo de moradores da Vila União é composto por 665 pessoas. Nesta pesquisa foram aplicados 137 questionários com moradores da comunidade. Como foi realizada uma amostragem por acessibilidade, a pesquisa é não-probabilística. Assim, seus resultados não podem ser generalizados para a totalidade da população da comunidade. A aplicação do questionário ocorreu de duas maneiras, online e presencial, e 
em dois períodos diferentes, com o objetivo de maximizar o número de respondentes e diversificá-los. A coleta de dados online foi realizada entre os dias 1 e 16 de dezembro de 2019, a partir da divulgação do questionário através do grupo de WhatsApp da associação de moradores. Já a coleta presencial foi realizada na própria comunidade por um dos pesquisadores e ocorreu entre os dias 19 de dezembro de 2019 e 17 de janeiro de 2020.

A tabulação dos dados foi feita usando a ferramenta de Formulários do Google e o software MS Excel, o qual também foi utilizado para analisar os dados obtidos e elaborar tabelas e gráficos. Os dados coletados foram analisados a partir da utilização de estatística descritiva. Ademais, foi realizada a dicotomização das variáveis-resposta das perguntas fechadas, a fim de calcular o coeficiente de correlação linear de Pearson e encontrar associações (SILVEIRA; ARDIGO, 2016). Tal análise levou em consideração a forma de aplicação do questionário (presencial ou online) para verificar se essa forma de aplicação influenciou nas respostas. As nuvens de palavras foram geradas com o auxílio da ferramenta gratuita online Word Cloud Generator.

\section{Resultados e Discussóes}

Nesta sessão são apresentados os resultados da etapa quantitativa da pesquisa na seguinte ordem: perfil demográfico dos respondentes; principais associações da imagem percebida da OMD e PMSC; importância da OMD e PMSC para a comunidade Vila União e confiança na PMSC atualmente; avaliação da OMD e atuação da PMSC; e as percepções da Vila União antes e depois da OMD.

\subsection{Perfil Demográfico}

O perfil demográfico dos respondentes foi estabelecido a partir do bloco de questões demográficas, referentes ao gênero, idade, ocupação, nível de escolaridade, renda pessoal mensal, idade e tempo em que mora na comunidade da Vila União. Os resultados são apresentados na Tabela 1 . 
Tabela 1 - Dados demográficos dos respondentes

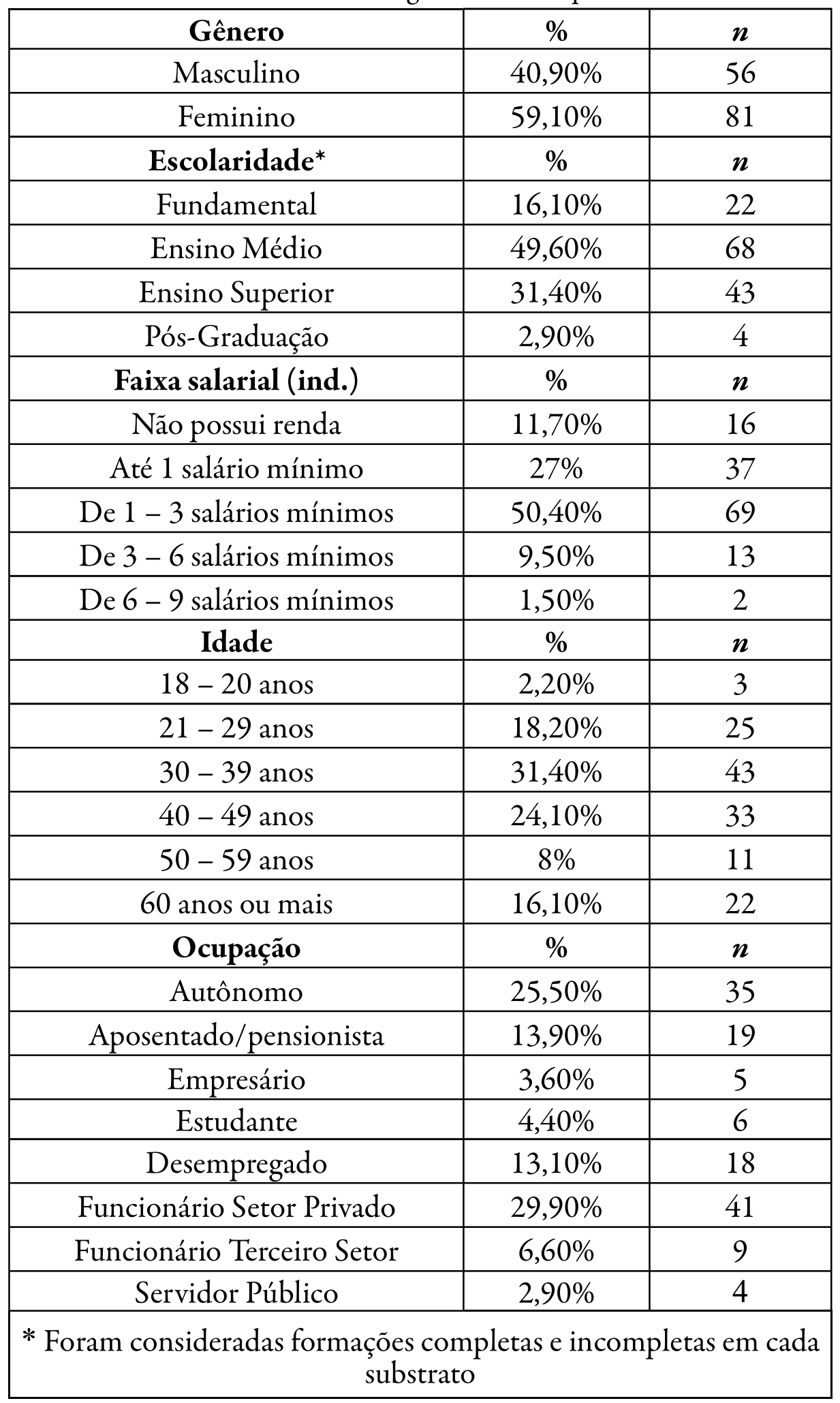

Fonte: Dados da pesquisa, 2020.

Conforme dados apresentados, $\mathbf{5 9 , 1 \%}$ dos respondentes são indivíduos do gênero feminino. A faixa etária de maior incidência de 
respondentes concentra-se no intervalo entre 30 - 39 anos, correspondendo a 31,4\% dos respondentes. Somadas a esta as faixas etárias entre 21 - 29 anos e 40 - 49 anos, nota-se que $73,7 \%$ da amostra possui entre 21 e 49 anos. Com relação a faixa salarial individual, a resposta que concentrou um maior número de indivíduos compreende a faixa de 1 a 3 salários mínimos com $\mathbf{5 0 , 4 \%}$. Quanto ao tempo de residência na comunidade, $63,5 \%$ dos respondentes afirmaram que residem há " 5 anos (e 1 dia) ou mais".

No que tange à ocupação dos respondentes, a principal ocupação indicada pela amostra pesquisada foi "Funcionário da Iniciativa Privada”, representando 29,9\% dos indivíduos. Apesar disso, é interessante destacar que a categoria "Aposentados/pensionistas" foi a terceira mais indicada pelos respondentes, seguida da opção "Desempregado", de forma que o somatório de ambas as ocupações resultou em $\mathbf{2 7 \%}$ dos indivíduos. Nesse sentido, é possível supor que mais de um quarto dos entrevistados vivenciam mais intensamente o cotidiano da comunidade, visto que não possuem ocupações formais.

Quanto à escolaridade dos entrevistados, a maioria possui nível médio completo ou incompleto, correspondendo a $49,6 \%$ das pessoas. A formação de nível superior completo ou incompleto foi assinalada por $\mathbf{1 6 , 1 \%}$ dos respondentes, ao passo que apenas $\mathbf{2 , 9 \%}$ da amostra afirmou possuir pós-graduação completa ou incompleta. É relevante destacar que esses dados convergem com aqueles sobre a educação brasileira, publicados pela OCDE (Organização para Cooperação e Desenvolvimento Econômico) em 2019 no Education at a Glance, que apontam que $18 \%$ dos adultos possuem educação superior no Brasil e apenas $0,8 \%$ possuem pós-graduação.

\subsection{Principais Associaçóes de Palavras com a Omd e PMSC}

A utilização de perguntas abertas para o mapeamento de associação de palavras com a organização é uma metodologia habitual em pesquisas de imagem (SCHULER; TONI, 2015). Nesse sentido, haviam duas perguntas no questionário: "Quando se fala em Operação Mãos Dadas, qual a primeira palavra ou imagem que lhe vem à 
cabeça?" e "Quando se fala em Polícia Militar, qual a primeira palavra ou imagem que lhe vem à cabeça?". As três principais respostas a cada uma dessas perguntas pode ser verificada na Tabela 2 .

Tabela 2 - Três principais associações referentes a Operação Mãos Dadas e a Polícia Militar de Santa Catarina

\begin{tabular}{|c|c|c|c|}
\hline \multicolumn{2}{|c|}{ Associações Operação Mãos Dadas } & \multicolumn{2}{|c|}{ Associações PMSC } \\
\hline Palavras & $\boldsymbol{n}$ & Palavras & $\boldsymbol{N}$ \\
\hline Segurança & 25 & Segurança & 58 \\
\hline $\mathrm{Paz}$ & 21 & Proteção & 7 \\
\hline União & 12 & Tranquilidade & 3 \\
\hline
\end{tabular}

Fonte: Dados Primários, 2020.

Com relação a Operação Mãos Dadas, $\mathbf{1 8 \%}$ dos entrevistados a associam com a palavra "segurança", 15\% da amostra associa com o vocábulo "paz" e 9\% com "união". Além destas, outras palavras foram atribuídas a operação, as quais podem ser visualizadas através da nuvem de palavras apresentada na Figura 1.

Figura 1 - Nuvem de Palavras associada à Operação Mãos Dadas

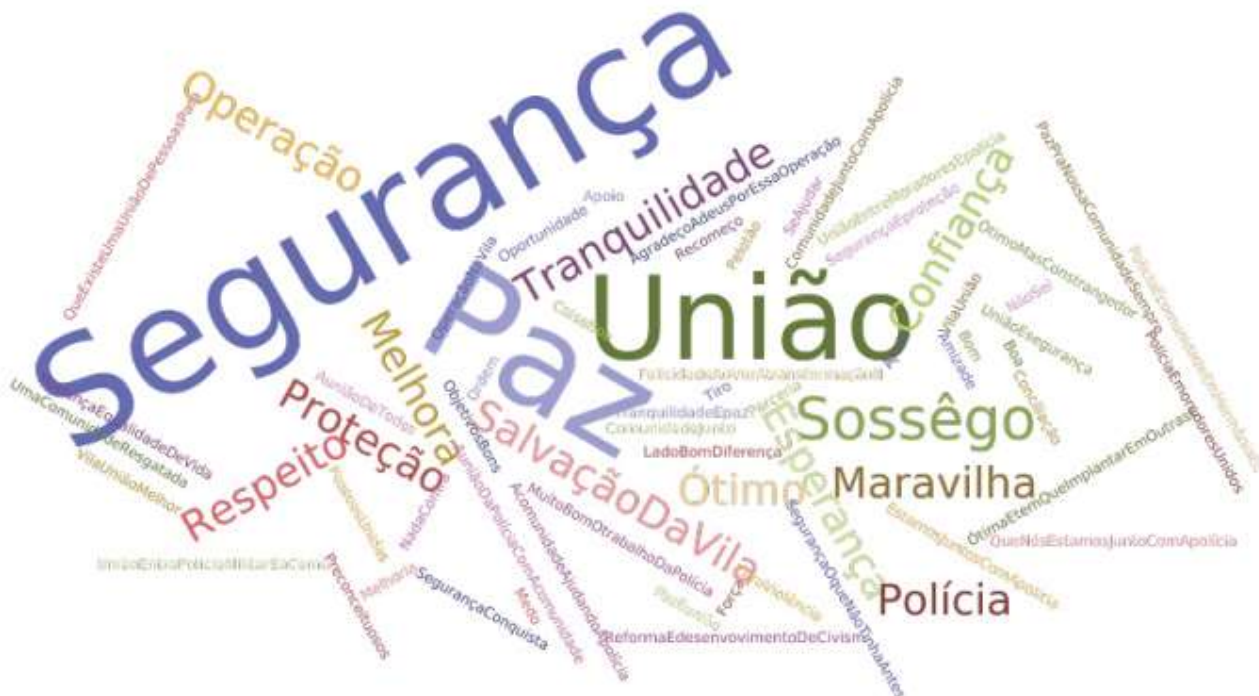

Fonte: Dados Primários, 2020

Quanto aos termos mais associados à Polícia Militar, conforme observado na Tabela 2, houve a prevalência da palavra "seguran- 
ça”, correspondendo a $\mathbf{4 2 \%}$ das respostas. O segundo vocábulo mais frequentemente associado à PMSC foi "proteção", apontado por sete pessoas. Em terceiro lugar, a palavra "tranquilidade" foi apontada em 3 respostas. A nuvem de palavras associadas à PM está na Figura 2.

Através das nuvens de palavras, é possível notar que algumas respostas incluíram mais de uma palavra, as quais constituíram uma única resposta, a exemplo de "segurança e tranquilidade" que foi considerada diferente das respostas "segurança" e "tranquilidade". Além disso, é possível notar que poucas palavras negativas foram relacionadas tanto com a PMSC quanto com a OMD.

É digno de destaque o fato de que a palavra "segurança", associada à imagem da Polícia Militar de Florianópolis, também ter se mostrado prevalente na pesquisa de Santos et al. (2019) sobre a imagem desta na Grande Florianópolis. Santos et al. (2019) consideraram que a associação de segurança à polícia indica uma imagem corporativa neutra por parte dos respondentes, pelo fato de que promover a segurança é uma das atribuições da PMSC.

Figura 2 - Nuvem de palavras associadas à Polícia Militar/SC

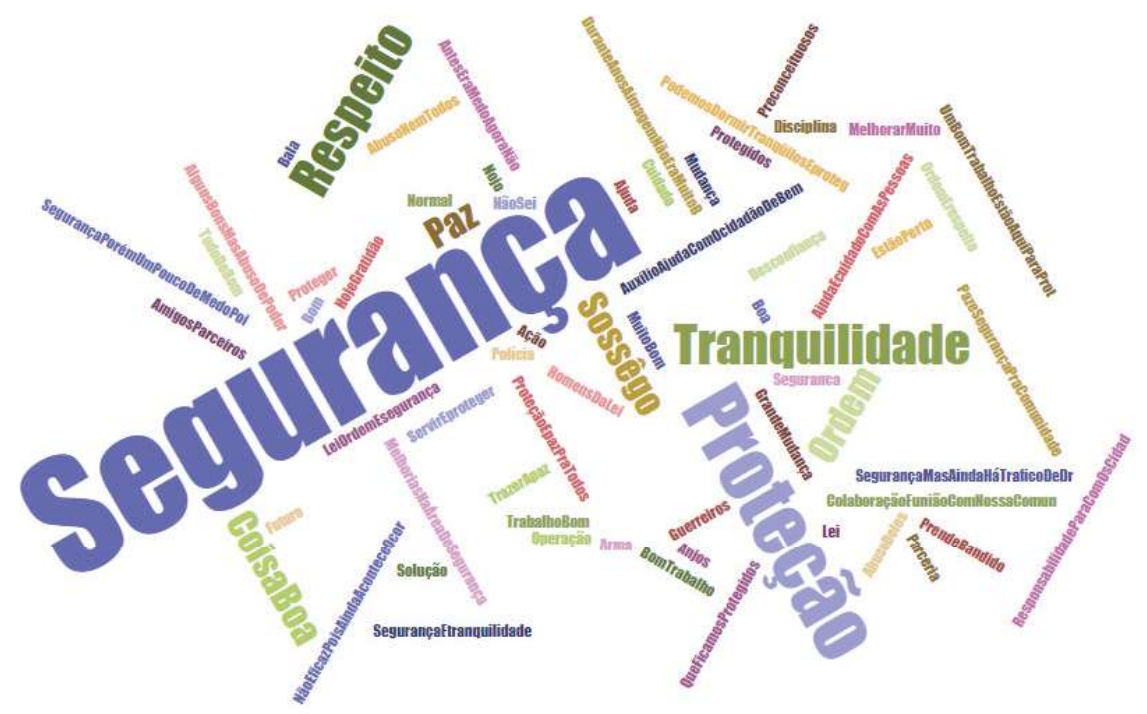

Fonte: Dados da pesquisa, 2020.

\subsection{IMPORTÂNCIA DA OMD E PMSC PRA COMUNIDADE DA Vila União e CONFiança ATUal Na PM}


A confiança na PMSC foi questionada através da pergunta "Quanto você confia (hoje) na PMSC?" cuja resposta consistia em uma escala variando entre 0 e 10 , na qual 0 significava "não confio" e 10 representava "confio totalmente". A média ponderada da nota atribuída à confiança atual na Polícia Militar pelos respondentes foi de $\mathbf{8 , 4}$. A maior frequência de respostas foi a nota 10 , ou seja, na afirmação de que confiam totalmente na Polícia Militar, concentrando $\mathbf{4 2 \%}$ da amostra. Como as demais notas apresentam frequências menores do que a anterior, conforme apresentado no Gráfico 1, optou-se por dividi-las em faixas para análise. A faixa que compreende as notas de 7 a 9 foi apontada por $\mathbf{4 5 \%}$ indivíduos. As notas entre 4 e 6 , contabilizaram $\mathbf{9 \%}$ das respostas. Apenas $\mathbf{4 \%}$ dos indivíduos atribuíram notas de 0 a 4 relacionadas com a confiança na PM. Os dados apresentados demonstram que a PMSC é uma instituição bastante confiável para a amostra estudada dos moradores da Vila União.

Gráfico 1 - Confiança atual da amostra na Polícia Militar

\section{Soma de 8-Em uma escala de 0 a 10 sendo $0=$ Não confio e $10=$ Confio totalmente quanto.}

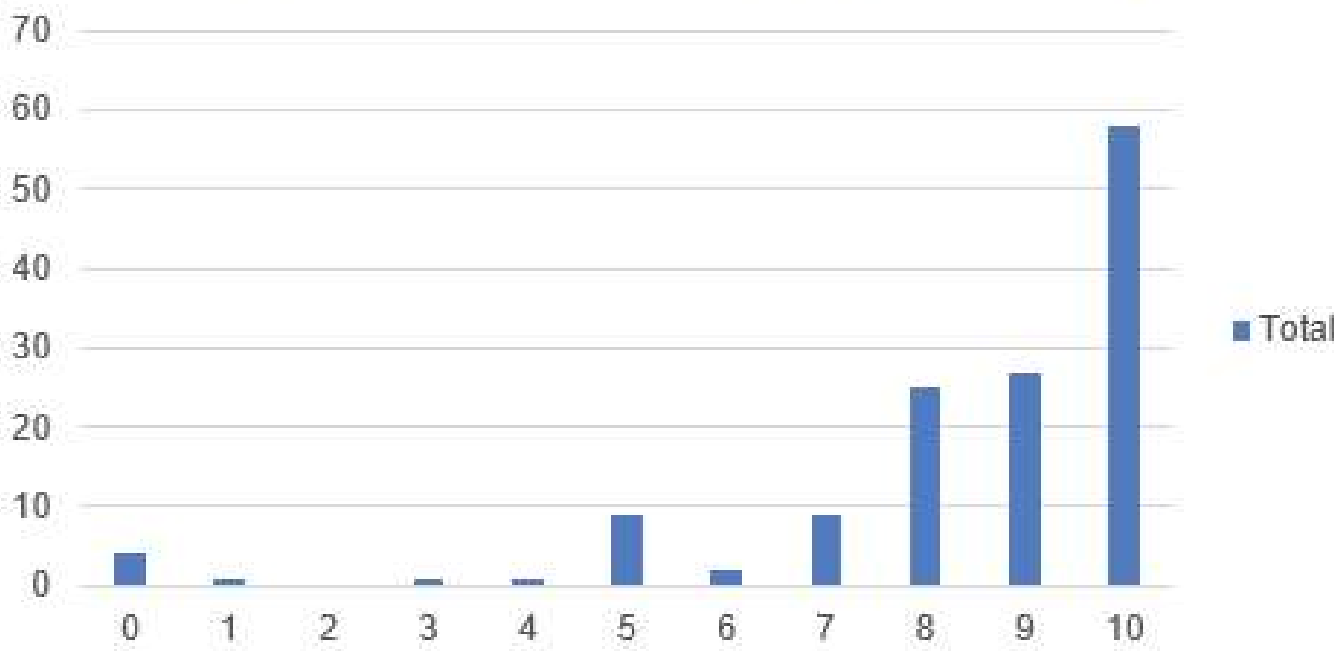

Escala

Fonte: Dados da pesquisa, 2020.

Com relação a importância da PMSC, perguntou-se o quão importante a PMSC era considerada para a comunidade da Vila União. As respostas poderiam ser atribuídas dentro de uma escala de 0 a 10 , na qual 0 significava "nenhuma importância" e 10 "muita importância". A maioria dos respondentes, $\mathbf{8 7 \%}$ destes, disseram que a PMSC é muito 
importante para a comunidade, ou seja, avaliaram a Polícia com a nota máxima dez. As notas entre 7 e 9 , correspondem a $13 \%$ dos respondentes, ao passo que cerca de $\mathbf{2 \%}$ atribuíram notas entre 0 e 6 .

A média ponderada da nota atribuída à importância da Polícia Militar de Santa Catarina para a comunidade da Vila União foi de 9,64. Conforme evidenciado no Gráfico 2, a PMSC é considerada como importante para a comunidade Vila União de acordo com os respondentes.

Gráfico 2 - Importância da PMSC para a comunidade da Vila União

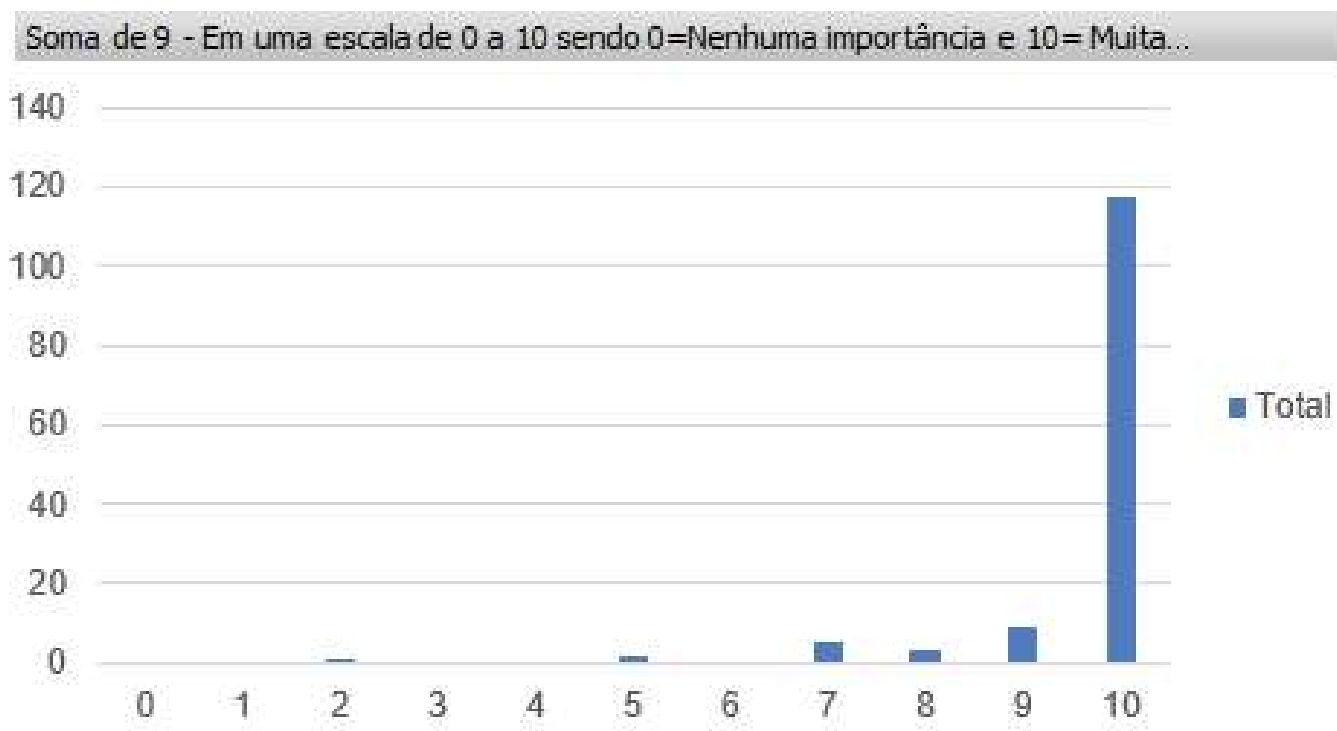

Escala

Fonte: Dados da pesquisa, 2020

No que se refere à importância da Operação Mãos Dadas, os entrevistados deveriam utilizar uma escala de 0 a 10 para responder quão importante consideram a operação. A maioria dos respondentes, $\mathbf{8 8 \%}$ dos indivíduos, apontaram que a Operação Mãos Dadas é muito importante para a comunidade, atribuindo nota dez. Nota entre 7 e 9 corresponderam a $\mathbf{7 \%}$ das respostas, e cerca de $\mathbf{5 \%}$ dos indivíduos atribuíram uma nota entre 0 a 6 . A média ponderada da importância da Operação Mãos Dadas para a comunidade da Vila União foi de 9,6. O Gráfico 3 ilustra a importância dada para a OMD de acordo com a visão dos entrevistados. 
Gráfico 3 - Importância da Operação Mãos Dadas para a comunidade da Vila União

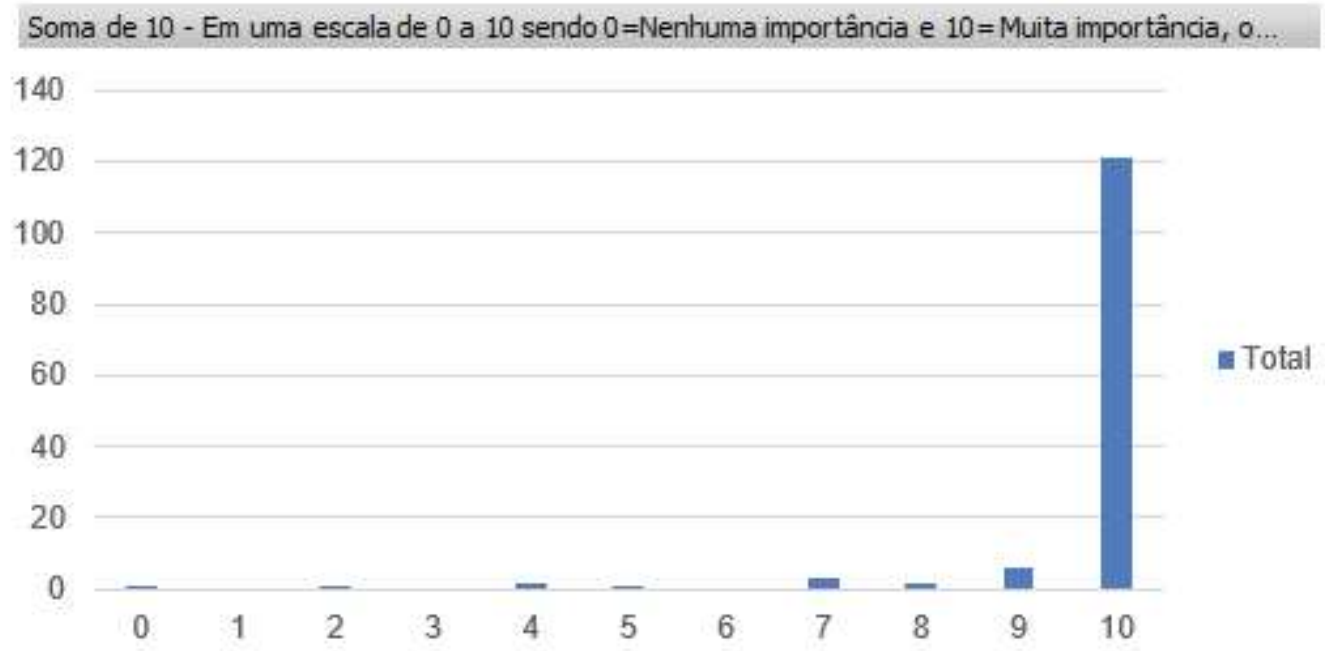

Fonte: Dados da pesquisa, 2020.

\subsection{Avaliação da Operação Mãos dadas e atuação DA PMSC}

Com o objetivo de avaliar tanto a Operação Mãos Dadas quanto a atuação da PMSC nela, houve a necessidade de, primeiro, identificar quais dos respondentes tinham um conhecimento mais aprofundado das atividades da operação. Para tal, foi questionado sobre a participação em alguma das atividades promovidas pela OMD, tanto por parte do entrevistado, quanto pelos seus filhos e/ou netos. Nesse sentido, $\mathbf{7 2 \%}$ responderam que "Sim", eles, seus filhos ou netos já haviam participado. A distribuição de respostas pode ser observada no Gráfico 4. 
Gráfico 4 - Participação dos respondentes ou filhos/netos destes na OMD

\section{Contagem de 5 - Você ou/e seu filho/neto (a) participa ou..}

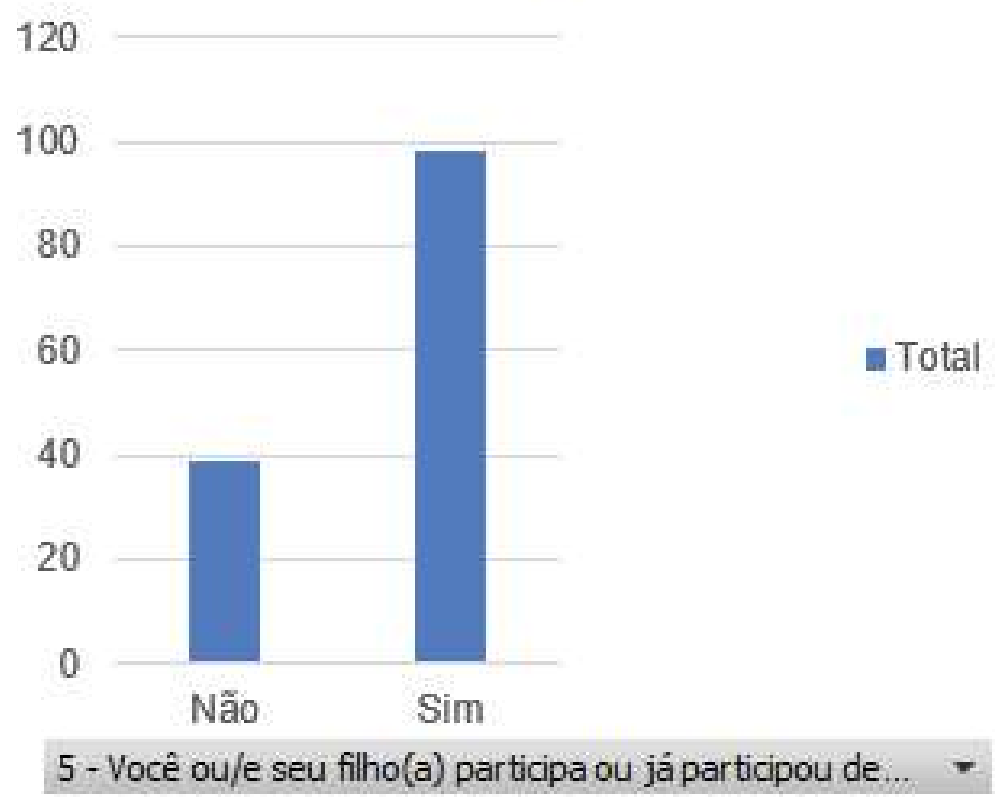

Fonte: Dados da pesquisa, 2020.

Sendo assim, as perguntas referentes a avaliação das atividades da Operação Mãos Dadas, bem como a avaliação da PMSC na OMD, foram feitas apenas para os 98 indivíduos que tiveram um contato mais próximo com a operação, por meio de participação pessoal ou de seus filhos/netos.

No que tange a avaliação da Operação Mãos Dadas, foram utilizados os seguintes termos na escala avaliativa: "Muito ruim"; "Ruim"; "Nem bom/nem ruim"; "Bom"; "Muito bom" e "Não sei opinar". Nesse sentido, 96,9\% dos 98 respondentes que já participaram ou tiveram filhos/netos que participaram das atividades da Operação Mãos Dadas avaliaram como "Muito bom" ou "Bom", conforme apresentado no Gráfico 5. Ou seja, existe uma avaliação positiva da operação por aqueles que tiveram um contato mais próximo a ela.

Gráfico 5 - Avaliação da Operação Mãos Dadas por aqueles que participaram ou tiveram filhos/netos que participaram de atividades promovidas pela OMD 


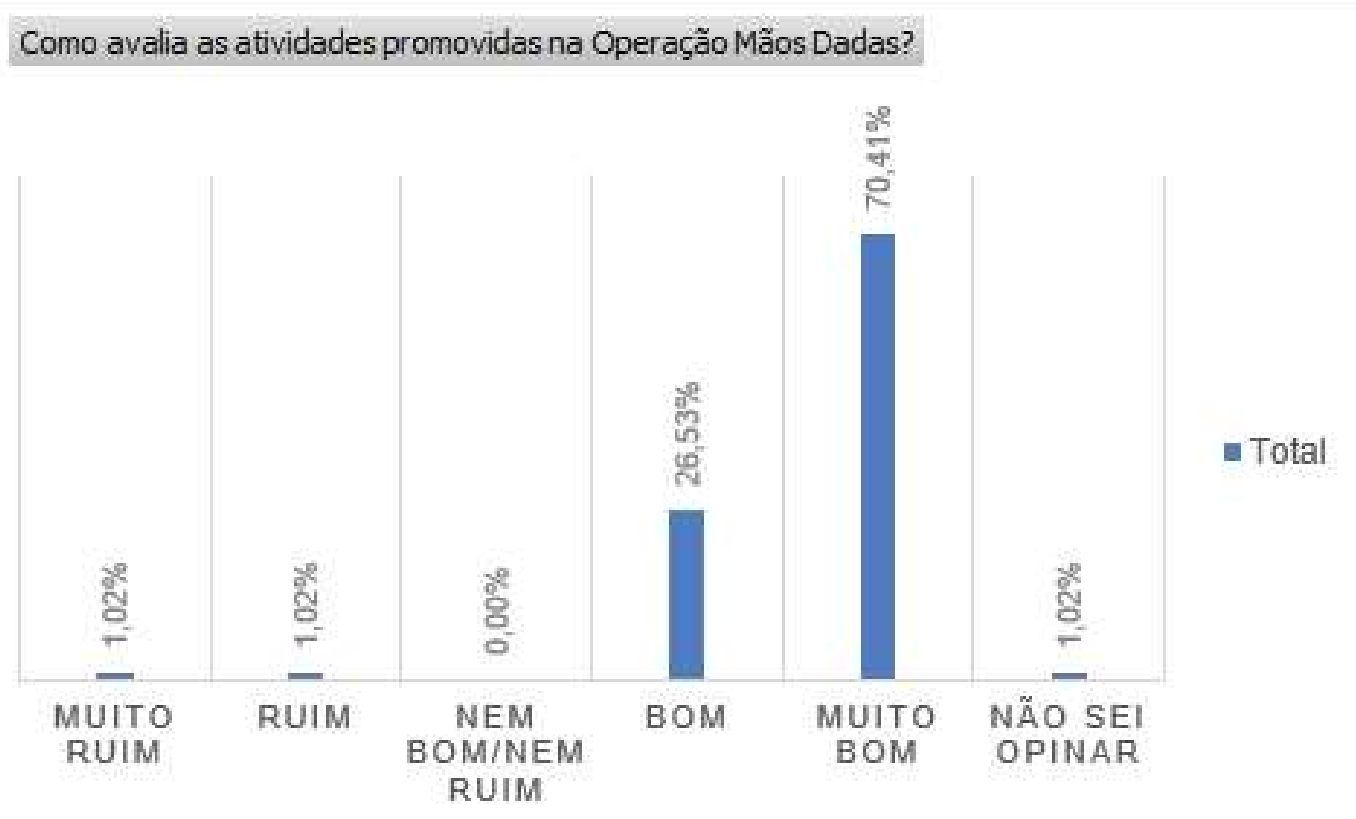

Fonte: Dados da pesquisa, 2020.

Além da avaliação da OMD, os respondentes foram questionados acerca da avaliação da atuação da PMSC na Operação Mãos Dadas, os seguintes termos foram utilizados na escala avaliativa: "Muito ruim"; "Ruim"; "Nem bom/nem ruim"; "Bom"; "Muito bom" e "Não sei opinar". Sendo assim, dos 98 respondentes que já participaram ou tiveram familiares próximos que participaram das atividades da Operação Mãos Dadas, $\mathbf{8 9 \%}$ avaliaram a atuação da PMSC na OMD como "Bom" ou "Muito bom". O Gráfico 6 apresenta a frequência de respostas por categoria da escala, evidenciando que os respondentes consideram a atuação da PMSC na Operação Mãos Dadas como positiva. 
Gráfico 6 - Avaliação atuação da PMSC na OMD

\section{Como avalia a atuação da PMSC na Operação Mãos Dadas?}

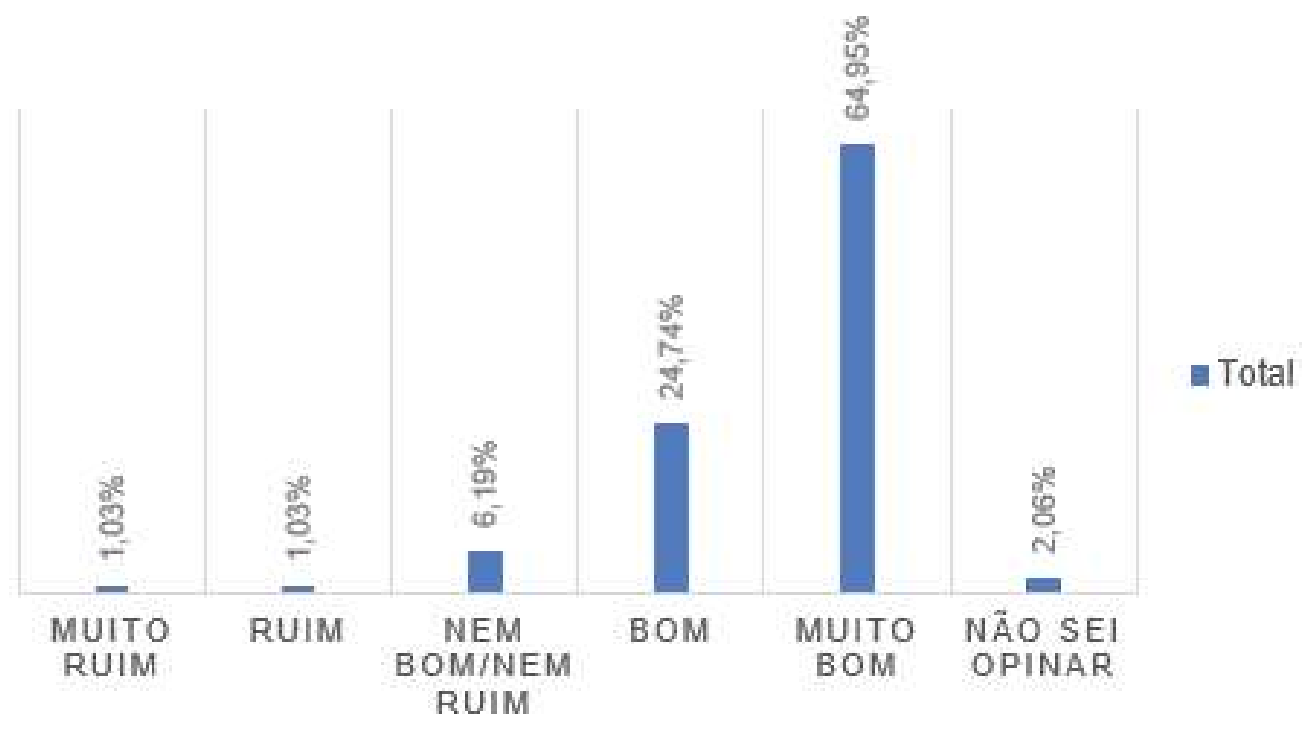

Fonte: Dados da pesquisa, 2020.

\subsection{Vila União antes e depois da Operação Mãos Dadas}

No intuito de elaborar um comparativo entre a situação da Vila União antes e depois da implementação da Operação Mãos Dadas, foram utilizadas quatro dimensões para avaliação por parte dos respondentes: Segurança na comunidade, Qualidade de vida, Convivência com a PMSC e Confiança na PMSC. As respostas utilizavam uma escala de avaliação que consistia de: "Muito ruim"; "Ruim"; "Nem bom/nem ruim"; "Bom"; "Muito bom" e "Não sei opinar".

No quesito segurança na comunidade, os dados obtidos demonstram um aumento significativo da segurança em relação a situação da Vila União anterior à Operação Mãos Dadas. Antes da OMD, a segurança da comunidade foi considerada como "Muito ruim" ou "Ruim" por 90,5\% dos respondentes, ao passo que depois da operação 74,4\% dos entrevistados consideram a segurança como "Boa" ou "Muito boa". O Gráfico 7 permite a visualização de cada uma das categorias de resposta antes e depois da implementação da OMD na Vila União, evidenciando a mudança de avaliação de uma forma positiva. 
Gráfico 7 - Segurança na Vila União antes e depois da OMD

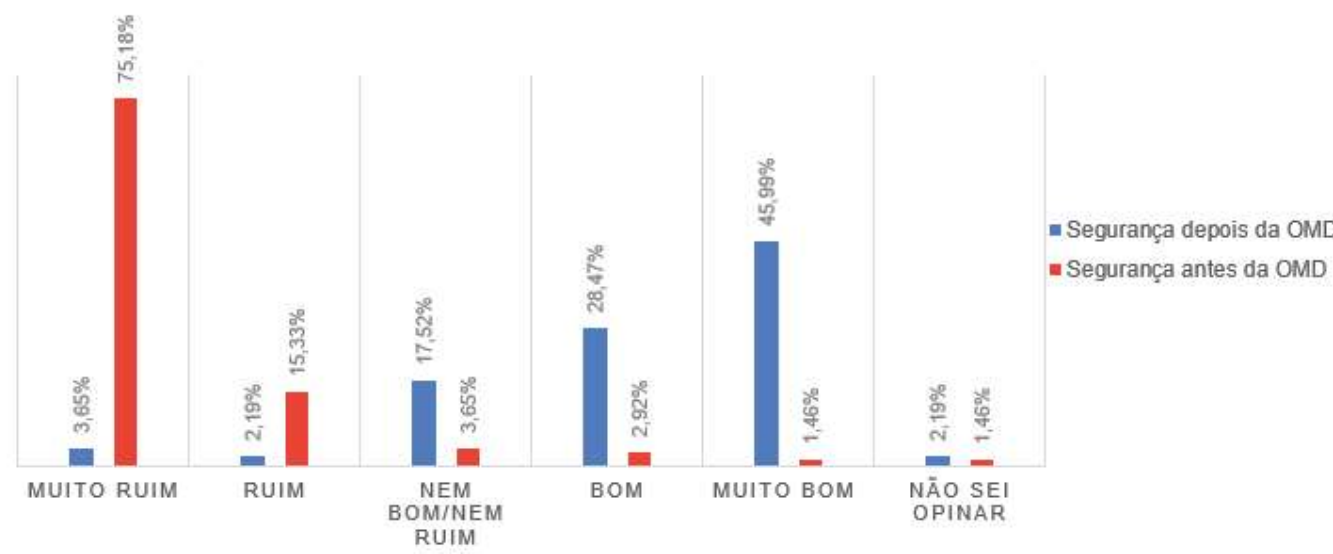

Fonte: Dados primários, 2020.

Quanto ao elemento “Qualidade de vida”, percebe-se o mesmo movimento observado na segurança da comunidade. Sendo assim, antes da Operação Mãos Dadas, os termos mais relacionados com esse aspecto foram "Muito ruim" ou "Ruim", com ocorrência de 77,3\%, se somados. Ao passo que, depois da Operação Mãos Dadas, a qualidade de vida, segundo a percepção dos respondentes, foi categorizada como "Bom" ou "Muito bom", somando o percentual de $73 \%$ das opiniões. O Gráfico 8 ilustra a mudança na percepção da qualidade de vida pelos respondentes da Vila União depois da implementação da OMD. 
Gráfico 8 - Qualidade de vida antes e depois da Operação Mãos Dadas

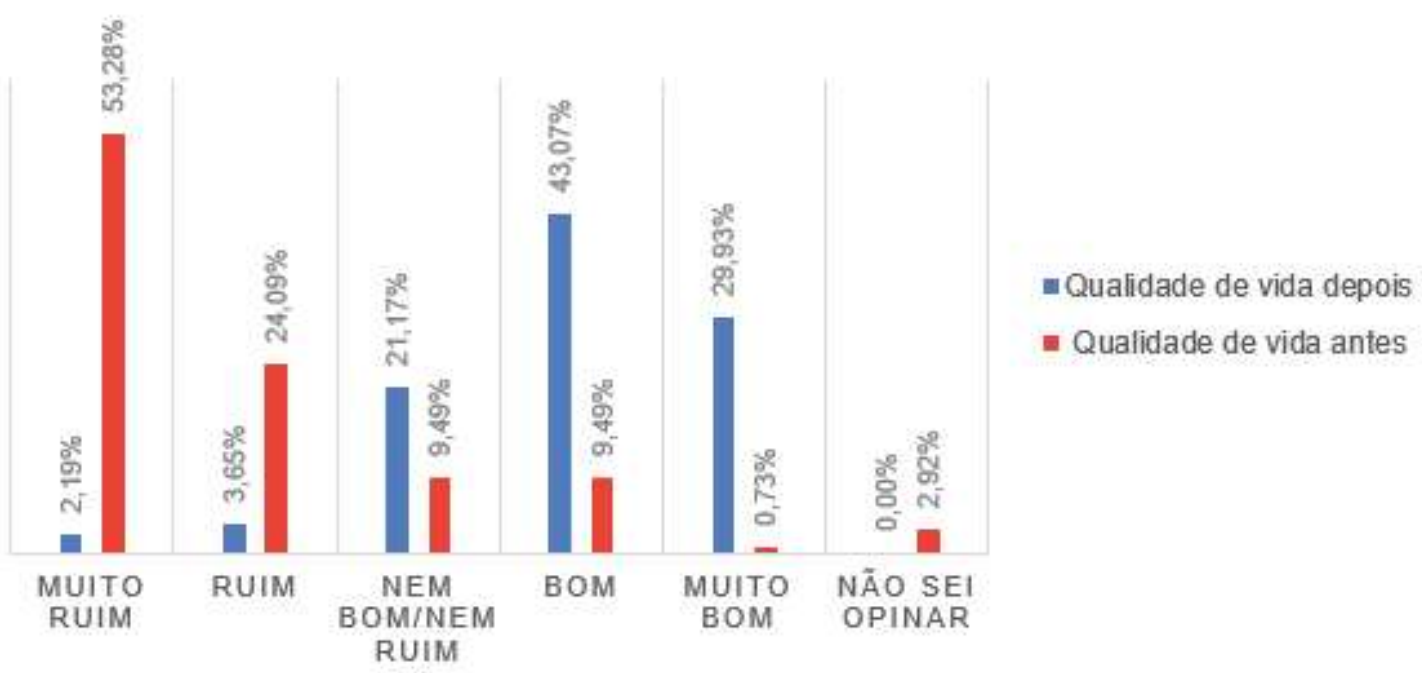

Fonte: Dados primários, 2020.

Com relação ao aspecto "convivência com a PMSC" também foi possível perceber uma melhora. Os respondentes indicaram que antes da Operação Mãos Dadas, a convivência com a PMSC era "Muito ruim" e "Ruim" em 52,5\% das respostas. Após a operação, as respostas que concentraram a maior frequência foram "Bom" e "Muito bom", as quais somadas resultam em $\mathbf{6 8 , 6 \%}$ da amostra. Além disso, a convivência com a PMSC foi classificada como "Nem bom/nem ruim" em ambos os contextos, porém, notou-se um decréscimo de $27,7 \%$ para 23,3\%, antes e depois da operação, respectivamente. O Gráfico 9 ilustra a mudança percebida de acordo com os entrevistados. 
Gráfico 9 - Convivência com a PMSC antes e depois da Operação Mãos Dadas

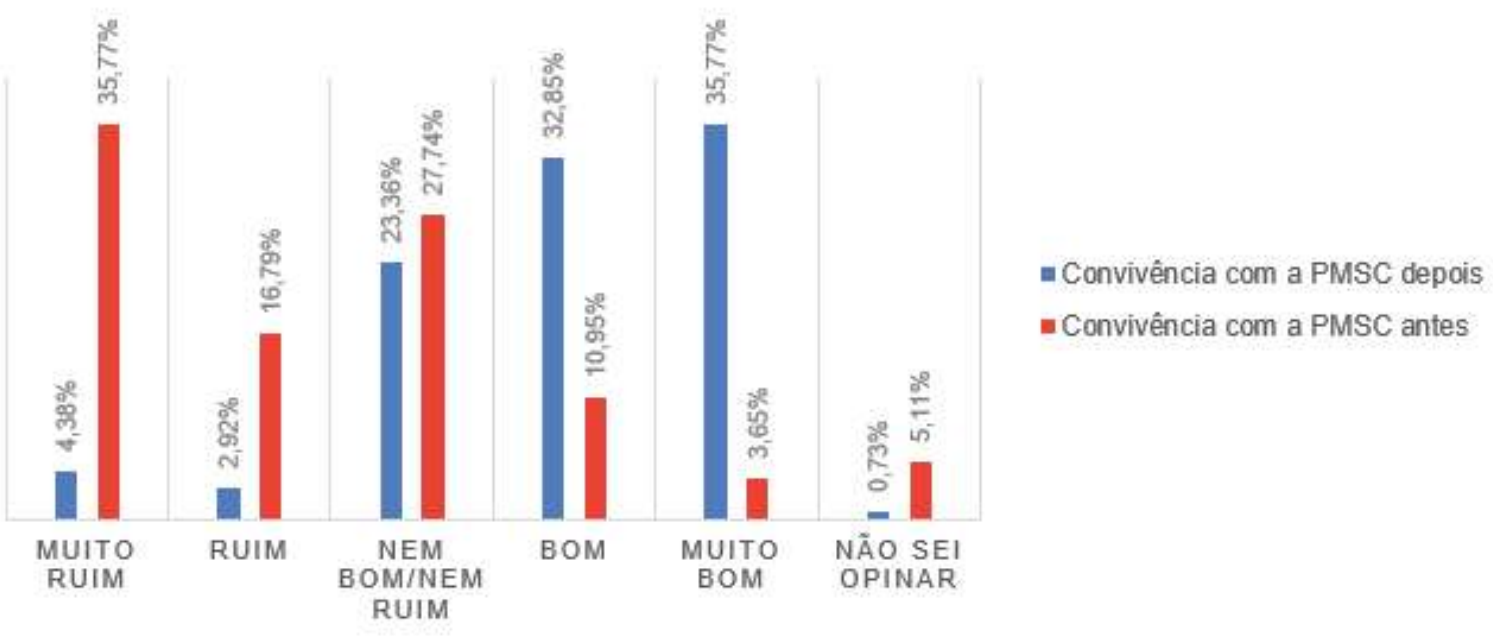

Fonte: Dados primários, 2020.

O último elemento considerado na pesquisa foi a "Confiança na PMSC" e, assim como já identificado nos elementos supracitados, identificou-se uma melhoria na percepção deste. Visto que os dados relacionados com a atribuição de nota para confiança na PMSC se mostraram positivos, é aceitável imaginar que o mesmo aconteceria nesta questão. De acordo com os dados obtidos, a confiança na PMSC antes da Operação Mãos Dadas era considerada como "Muito ruim" ou "Ruim" por 43,8\% dos entrevistados. Após a Operação Mãos Dadas, a confiança na PMSC passa a ser considerada com os elementos "Bom" e "Muito bom" da escala, totalizando em $\mathbf{6 5 \%}$ das respostas. A resposta "Nem bom/nem ruim" foi assinalada em ambos os contextos, sendo o anterior a OMD, 27\% e após a operação, 24\%. O Gráfico 10 ilustra os níveis de confiança na PMSC antes e depois da Operação Mãos Dadas. 
Gráfico 10 - Confiança na PMSC antes e depois da Operação Mãos Dadas

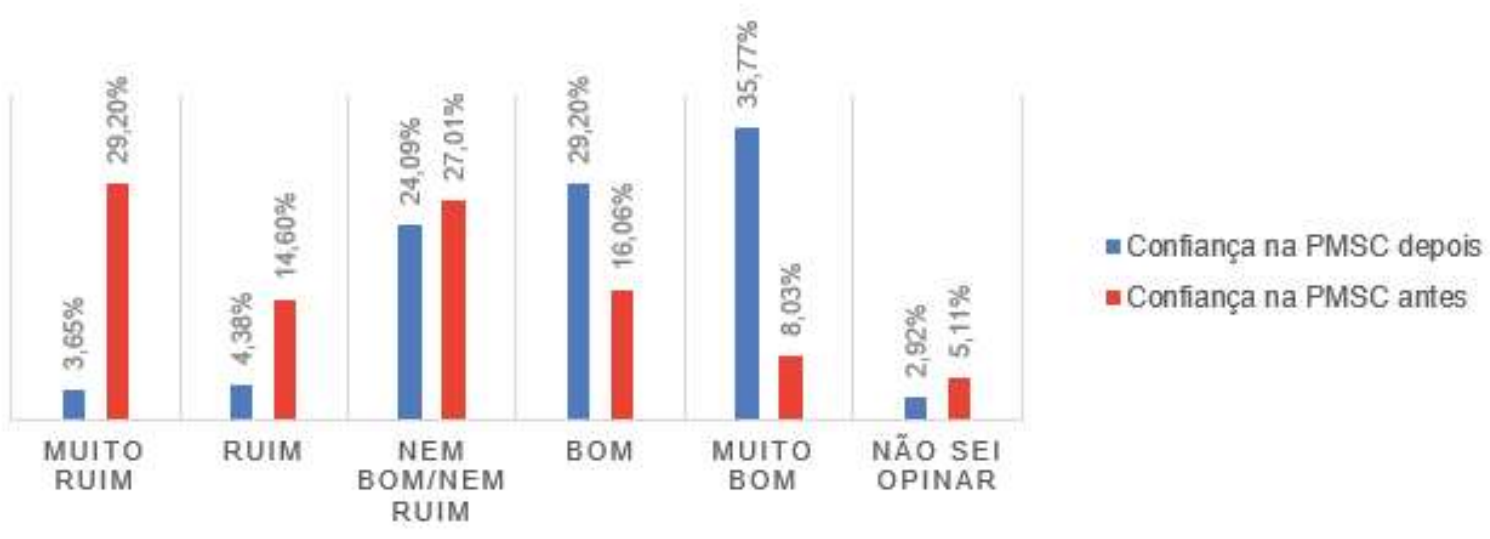

Fonte: Dados primários, 2020.

Os dados obtidos nesta pesquisa apontam a influência positiva da Operação Mãos Dadas na imagem percebida da PMSC. Dessa forma, supõe-se que a experiência de aproximação da Polícia Militar com a comunidade através da OMD, contribuiu para que os moradores da Vila União obtivessem um maior conhecimento sobre as atribuições da Polícia como instituição e isso culminou em um aumento de confiança da comunidade no trabalho da corporação. Isso converge com os resultados obtidos por Barros e Martins (2017), que revelaram que o conhecimento sobre o poder legislativo obtido pela participação no Parlamento Jovem Brasileiro melhorou a imagem pública dos jovens acerca do Poder Legislativo.

Dessa maneira, embora não indicadas especificamente no modelo de Tran et al. (2015) como elemento-chave para a formação de imagem corporativa, parece plausível indicar que ações sociais podem influenciar na imagem de uma organização de uma maneira positiva, devido ao seu impacto na percepção de confiança.

Ainda que o foco tenha sido a imagem, a presente pesquisa analisou componentes importantes tanto para a imagem quanto para a reputação de uma instituição - a PMSC. Em relação à reputação corporativa, conforme apontado por Ferreira e Luiz (2016), existem seis fatores constituintes: responsabilidade e confiança; reconhecimento; transparência; qualidade; coerência; e credibilidade. Ao passo que a imagem corporativa é criada a partir da interação de sete dimensões, identificadas por Tran et al. (2015), com a personalidade e comunica- 
ção corporativa. As sete dimensões são: aparência física, sentimentos positivos, ambiente, aparência online, aparência dos empregados, comunicações externas e, por fim, atitude e comportamento.

Os sentimentos da comunidade em relação a OMD e a PMSC, a diferença do ambiente antes e depois da implementação da operação, bem como a atitude em relação a polícia, indicam uma imagem positiva e a mudança da imagem da PMSC na percepção dos moradores da comunidade depois da implementação da OMD. Possivelmente, ao analisar individualmente os respondentes, se encontraria diferentes indivíduos em cada uma das etapas do modelo de Tran et al. (2015), inclusive aqueles que estão no nível advocacy, ou seja, que defendem e apoiam a OMD e a PMSC.

A confiança na PMSC e a importância dada pela comunidade para a instituição e para a Operação Mãos Dadas também indicam uma boa reputação. Tal inferência pode ser feita visto que a reputação corporativa envolve fatores como responsabilidade e confiança, reconhecimento, qualidade e credibilidade (FERREIRA; LUIZ, 2016). A qualidade e o reconhecimento podem ser percebidos pela melhora na percepção de segurança e qualidade de vida na comunidade. Responsabilidade e confiança, bem como credibilidade, podem ser percebidas tanto na melhora de percepção de confiança na PM e convivência com a polícia, quanto pela nota de percepção da importância da instituição para a comunidade e pela nota dada para a confiança na PMSC.

\subsection{Correlação de Pearson}

Conforme explicitado na metodologia, foi realizada a dicotomização das variáveis resposta a fim de investigar associações através do coeficiente de correlação linear de Pearson. No caso da modalidade de aplicação (presencial ou online), não foi constatada nenhuma associação estatisticamente significativa com alguma das respostas, visto que o coeficiente variou de $-0,34$ a 0,32 .

As associações moderadas e fortes foram observadas em respostas que indicam a consistência na aplicação do questionário. 


\section{Consideraçóens Finais}

A presente pesquisa analisou a imagem institucional da Polícia Militar de Santa Catarina no conjunto habitacional Vila União após a introdução da Operação Mãos Dadas. Ainda que não tenha se constituído de uma pesquisa longitudinal, abordou, por meio da utilização de perguntas, a percepção da população antes e depois da implementação da operação.

Dentre os achados mais relevantes relacionados ao objetivo do trabalho, está a percepção dos entrevistados sobre a situação da Vila União antes e depois da implementação da Operação Mãos Dadas. Nesse sentido, foram analisados quatro critérios: segurança na comunidade, qualidade de vida, convivência com a PMSC e confiança na PMSC. A percepção dos respondentes em relação às quatro dimensões apresentadas foi melhor após a OMD, dessa forma é possível sugerir que a operação influenciou na percepção dos moradores da Vila União acerca da Polícia Militar de uma forma positiva. Os achados convergem com as conclusões obtidas por Barros e Martins (2017), que indicam o aumento do conhecimento sobre uma área e seus órgãos públicos como um fator capaz de melhorar a imagem percebida.

É digno de destaque que a investigação visava também verificar o conhecimento da OMD pelos moradores locais, fato que não apenas foi confirmado, como também teve sua percepção de importância avaliada através do questionário. A resposta média da nota atribuída para a importância da operação foi 9,6 - evidenciando que ela é muito importante para os entrevistados da Vila União.

Uma metodologia básica aplicada a pesquisas de imagem é a associação de palavras, ressalta-se que a principal associação encontrada, tanto em relação a Operação Mãos Dadas quanto a PMSC, foi com a palavra "Segurança". Essa associação foi a mais prevalente também no estudo de Santos et al. (2019) em relação a Polícia Militar e, conforme indicado pelos autores, é uma associação neutra, pelo fato de que a segurança é uma atribuição da função policial.

Outro achado desta pesquisa refere-se ao fato de que, mesmo em sua fase inicial e exploratória, constatou-se um número limitado 
de estudos e pesquisas relacionados à temática de pesquisas de imagem organizacional no setor público. Tal fato indica que, ainda que exista a possibilidade de aplicação dessa metodologia na esfera pública, ela ainda não é utilizada amplamente, de forma que existe oportunidade para que mais pesquisas sejam desenvolvidas nesse sentido - sejam elas relacionadas à prática da pesquisa em organizações públicas ou ao desenvolvimento de metodologias adaptadas ao setor.

Adicionalmente, dentre os respondentes que indicaram a participação pessoal ou de familiares nas atividades promovidas pela Operação Mãos Dadas, a avaliação da OMD e atuação da Polícia Militar de Santa Catarina em tal operação, foi considerada positiva, isso evidenciado pelo fato de as respostas se concentrarem nas opções "Muito bom" e "Bom".

É importante mencionar dificuldades encontradas na coleta dos dados quantitativos, o que resultou em uma diminuição do tamanho da amostra inicialmente planejada. Sendo assim, existe a limitação de generalização dos resultados coletados. Ademais, a etapa qualitativa também se limitou em uma entrevista em profundidade, o que igualmente se constitui como limitação da pesquisa.

Dado os objetivos traçados, compreende-se que o corte longitudinal seria mais adequado ao caso. Entretanto, a motivação para realização da pesquisa ocorreu após o início da Operação Mãos Dadas, impossibilitando o uso do corte ideal. Assim, optou-se pelo corte transversal, fato que implicou na necessidade de o entrevistado recorrer à memória para responder em relação a sua percepção sobre a PMSC antes do início da Operação Mãos Dadas. Pontua-se, entretanto, que o intervalo entre a coleta de dados e o início da Operação Mãos Dadas foi de 14 meses, portanto, tempo plausível para o entrevistado pudesse recorrer à memória.

Este estudo traz informações importantes sobre o impacto que a Operação Mãos Dadas teve na percepção da imagem da PMSC na Vila União, fato especialmente relevante por ser uma forma de atuação pioneira da Polícia Militar. Com o sucesso da Operação Mãos Dadas na Vila União, confirma-se que a postura atual da atividade policial é voltada para a gestão de conflitos nas comunidades e afasta a visão 
deturpada de que as forças policiais executam funções apenas reativas (SILVA, 2020). Além disso, os achados sugerem que órgãos públicos, como a Polícia Militar, podem alcançar melhorias de imagem institucional percebidas pelos cidadãos a partir de ações sociais de envolvimento com as comunidades.

Recomenda-se que sejam realizados novos estudos com o objetivo de avaliar o impacto da OMD na imagem da PMSC em outras regiões que esta tenha sido implantada, como no Morro do Mocotó, em Florianópolis, e no Morro da Dona Edith, na cidade de Blumenau. Além destes, aconselha-se o desenvolvimento de novos estudos sobre o impacto de ações sociais na imagem dos órgãos públicos responsáveis por sua implementação nas comunidades, a fim de confirmar a indicação de que as ações sociais podem influenciar na imagem dos órgãos públicos que as promovem.

BIOGRAFIA DO(A)S AUTORE(A)S

Vinícius Paulo da Silva Costa

Graduando em Administração Pública da ESAG/

UDESC

\section{Aline Regina Santos}

Possui Doutorado em Engenharia de Produção e Sistemas, PPGEP/UFSC (2009), COM TESE NA ÁREA de Gestão da ReclamaÇão e Recuperação de Serviços,

Mestrado em Administração pelo Mestrado

Profissional em Administração do Centro de

Ciências em Administração e Socioeconômicas (ESAG) da Universidade do Estado de Santa Catarina

(UDESC) (2006) E GRADUAÇão EM AdMinistração PELA

Universidade Federal de Santa Catarina (2003).É

professora no Departamento de Administração Pública e no Mestrado Acadêmico em Administração DA ESAG/UDESC. ATUa COMO PESQuisadora E CONSULTORA, COM EXPERIÊNCIA NA ÁREA DE MARKETING de Serviços (Público e Privado).

\section{Juliane Pierri Ardigo}

Possui graduação em Administração pela Universidade do Estado de Santa Catarina (2019).

Durante a graduação atuou tanto no meio 


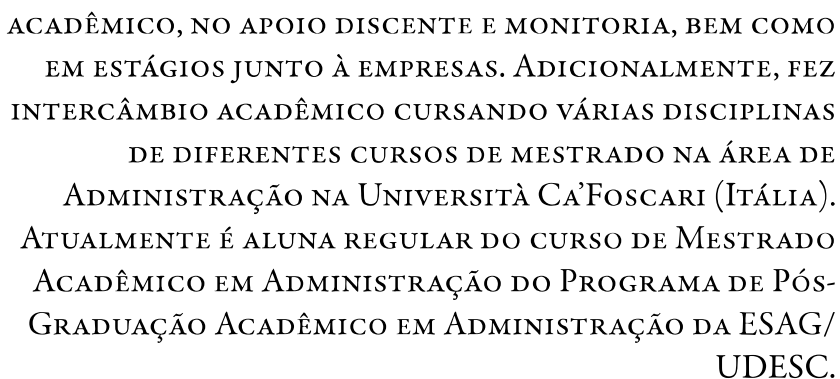

UDESC.

\section{REFERÊNCIAS}

BARROS, Antonio Teixeira de; MARTINS, Lúcio Meireles. Impactos do Parlamento Jovem brasileiro na imagem pública do Poder Legislativo na visão dos egressos. Revista do Serviço Público, [S.L.], v. 68, n. 1, p. 157-189, 31 mar. 2017. Escola Nacional de Administração Pública (ENAP). http://dx.doi.org/10.21874/rsp. v68i1.1234. Disponível em: https://revista.enap.gov.br/index.php/ RSP/article/view/1234/797. Acesso em: 24 set. 2020.

CHUN, Rosa. Corporate reputation: meaning and measurement. International Journal Of Management Reviews, [S. 1.], v. 7, n. 2, p. 91109, nov. 2005. Disponível em: https://onlinelibrary.wiley.com/doi/ abs/10.1111/j.1468-2370.2005.00109.x. Acesso em: 24 set. 2020.

DALMONECH, Hildo Anselmo Galter; GOULARTE, Marko Aurélio; RAMOS, Paulo Ferrare; MONTE-MOR, Danilo Soares. Factors that influence the indication of a public federal education institution by its students through buzz marketing. Revista Eletrônica de Ciência Administrativa, [S.L.], p. 55-68, 30 abr. 2016. IBEPES (Instituto Brasileiro de Estudos e Pesquisas Sociais). http://dx.doi. org/10.21529/recadm.2016003. Disponível em: https://doaj.org/art icle/2b867e8bef0842f2bd0cd11a78c54fe6. Acesso em: 25 set. 2020.

DAVIES, Jason. Word Cloud Generator. Disponível em: https:// www.jasondavies.com/wordcloud/. Acesso em: 15 mar. 2020.

FERREIRA, Ana Cristina et al. Índice de Reputação Corporativa: um estudo em uma instituição pública de ensino superior. Revista Reuna, Belo Horizonte, v. 21, n. 1, p. 5-28, jan.-mar. 2016. Disponível em: https://revistas.una.br/reuna/article/view/683/0. 
Acesso em: 25 set. 2020.

GOMES, Mauro Tapias; SAPIRO, Arão. Imagem Corporativa uma vantagem competitiva sustentável. Revista de Administração de Empresas, São Paulo, v. 33, n. 6, p. 84-96, nov./dez. 1993. Disponível em: https://www.scielo.br/pdf/rae/v33n6/a09v33n6.pdf. Acesso em: 21 set. 2020 .

LAURINDO, Larissa. Pesquisa de imagem da Polícia Militar de Santa Catarina: um estudo ampliado. 2018.67 f. TCC (Graduação) - Curso de Administração Pública, Universidade do Estado de Santa Catarina, Florianópolis, 2018. Disponível em: http://sistemabu. udesc.br/pergamumweb/vinculos/000066/0000660a.pdf. Acesso em: 15 out. 2019.

LOADER, Ian. Consumer Culture and the Commodification of Policing and Security. Sociology, [S.1.], v. 33, n. 2, p. 373-392, maio 1999. SAGE Publications. Disponível em: http://dx.doi. org/10.1177/s003803859900022x.

MACHADO, Aderbal. Operação Mãos Dadas da PM. Disponível em: http://www.aderbalmachado.com.br/noticia/2018-08-19/ Operacao_Maos_Dadas_da_PM. Acesso em: 15 out. 2019.

MALHOTRA, Naresh K. Pesquisa de marketing: uma orientação aplicada. 6. ed. São Paulo: Bookman, 2012.

MATTAR, Fauze Najib. Pesquisa de marketing: metodologia, planejamento. 6. ed. São Paulo: Atlas, 2005.

NUNES, Glaucio Santoro; VEIGA, Jordana Luiza Barbosa da Costa; BARRETO, Daniela Faria da Costa; BOAS, Ana Alice Vilas. Motivação: o estudo dos fatores que influenciam os indivíduos a optar por ingressar em organização do setor público, do ramo de energia. Gestão \& Regionalidade, [S. I.], v. 24, n. 72, p. 38-47, set.-dez. 2008. Disponível em: http://seer.uscs.edu.br/index.php/ revista_gestao/article/viewFile/98/61. Acesso em: 15 out. 2019. OECD. Education at a Glance. 2019. Disponível em: https://www. oecd.org/education/education-at-a-glance/EAG2019_CN_BRA. pdf. Acesso em: 23 set. 2020.

PESSOA, Fabíola Gostek. Pesquisa de Imagem da Polícia Militar de Santa Catarina: uma análise da imagem da instituição na 
Grande Florianópolis. 2017. 47 f. TCC (Graduação) - Curso de Administração Pública, Universidade do Estado de Santa Catarina, Florianópolis, 2017. Disponível em: http://sistemabu.udesc.br/ pergamumweb/vinculos/000042/000042b9.pdf. Acesso em: 15 out. 2019.

\section{PREFEITURA MUNICIPAL DE FLORIANÓPOLIS. Diagnóstico} das áreas de interesse social. 2006. Disponível em: http://portal.pmf. sc.gov.br/arquivos/arquivos/pdf/24_05_2010_17.26.43.563188c89 583efcf3b79164708b3cd5c.pdf. Acesso em: 15 out. 2019.

RAMALHO, Wanderley ; RESENDE, Luciana Matos. Reputação em serviço público de transporte. Revista Gestão \& Tecnologia, Pedro Leopoldo, v. 16, n. 2, p. 218-237, mai./ago. 2016. Disponível em: http://www.spell.org.br/documentos/ver/42766/reputacao-emservico-publico-de-transporte. Acesso em: 15 out. 2019.

SANTOS, Aline Regina; PESSÔA, Fabíola Gostek; RODRIGUES, Ana Paula Grillo. A Imagem Corporativa e seus Reflexos: um estudo de imagem da polícia militar de Santa Catarina na perspectiva de moradores da Grande Florianópolis. Teoria e Prática em Administração, [S.1.], v. 9, n. 1, p. 63-76, 22 mar. 2019. ANPAD. http://dx.doi.org/10.21714/2238-104x2019v9i1-39583. Disponível em: https://doaj.org/article/7ddd4ef0d4404a828e50ec433e2df1da? frbrVersion=2. Acesso em: 21 set. 2020 .

SANTOS, Aline Regina; COSTA, Jane Iara Pereira da; BURGER, Fabrício; BORJA, Guilherme Régis de. Quem conhece as ouvidorias públicas? um estudo sobre a imagem percebida por cidadãos de Florianópolis (SC). Cadernos Gestão Pública e Cidadania, [S.1.], v. 22, n. 73, p. 400-420, 17 dez. 2017. Fundação Getúlio Vargas. http:// dx.doi.org/10.12660/cgpc.v22n73.66025. Disponível em: http:// bibliotecadigital.fgv.br/ojs/index.php/cgpc/article/view/66025. Acesso em: 21 set. 2020.

SAUERBRONN, João Felipe Rammelt; LODI, Marluce Dantas de Freitas. Construção da imagem institucional do Poder Judiciário - uma análise baseada nas campanhas publicitárias do Conselho Nacional de Justiça. Cadernos Ebape.Br, [S.I.], v. 10, n. 4, p. 925-945, dez. 2012. FapUNIFESP (SciELO). http://dx.doi.org/10.1590/ s1679-39512012000400010. Disponível em: https://www.scielo.br/ 
scielo.php?script $=$ sci_arttext\&pid $=\$ 1679-39512012000400010$. Acesso em: 24 set. 2020.

SCHULER, Maria.; TONI, Deonir de. Gestão da imagem de organizações, marcas e produtos: através do MCI. São Paulo: Atlas, 2015.

SEVERINO, Antônio Joaquim. Metodologia do trabalho cientifico. 23. ed. São Paulo: Cortez, 2007.

SILVA, Geélison Ferreira da; RIBEIRO, Ludmila Mendonça Lopes. Confiança nas instituições democráticas e vitimização por crime: qual a relação?. Revista de Sociologia e Politica, [S.l.], v. 24, n. 58, p. 59-84, jun. 2016. FapUNIFESP (SciELO). http://dx.doi.org/10.1590/1678-987316245803. Disponível em: https://www.scielo.br/scielo.php?script=sci_arttext\&pid $=$ S0104-44782016000200059. Acesso em: 24 set. 2020 .

SILVA, José Orlando Sousa da; JERÔNIMO, Taciana de Barros; MELO, Fagner José Coutinho de; AQUINO, Joás Tomaz de. Planejamento estratégico: elaboração do plano operativo na central de abastecimento farmacêutico de um município de Pernambuco. Rabis, [S.l.], v. 13, n. 4, p. 30-54, 22 maio 2017. RAHIS - Revista de Administração Hospitalar e Inovação em Saúde. http://dx.doi. org/10.21450/rahis.v13i4.3711. Disponível em: http://www. spell.org.br/documentos/ver/45481/planejamento-estrategico-elaboracao-do-plano-operativo-na-central-de-abastecimentofarmaceutico-de-um-municipio-de-pernambuco---. Acesso em: 24 set. 2020.

SILVA, Luciano Loiola da. O emprego das forças policiais como instância mediadora de conflitos. Revista Brasileira de Ciências Policiais, Brasília, v. 11, n. 1, p. 101-131, abr. 2020. Disponível em: https://periodicos.pf.gov.br/index.php/RBCP/article/view/699. Acesso em: 12 maio 2021.

SILVA, Luísa Dominoni Diogo da. Você Conhece a Polícia Militar de Santa Catarina?: um estudo sobre a imagem da PMSC na percepção dos cidadão das Grande Florianópolis. 2017. 35 f. TCC (Graduação) - Curso de Administração Pública, Universidade do Estado de Santa Catarina, Florianópolis, 2017. Disponível em: http://sistemabu. udesc.br/pergamumweb/vinculos/000042/000042be.pdf. Acesso 
em: 15 out. 2019 .

SILVA, Sabrina Severo da. Movimento Aroeira: práticas pedagógicas e juventude em Florianópolis - uma alternativa à violência e à criminalidade. 2010. 169 f. Dissertação (Mestrado) - Curso de Programa de Pós-Graduação em Educação, Universidade Federal de Santa Catarina, Florianópolis, 2010. Disponível em: https://repositorio.ufsc.br/xmlui/bitstream/ handle/123456789/94413/287678.pdf ?sequence=1\&isAllowed=y. Acesso em: 26 ago. 2019.

SILVEIRA, Luhilda Ribeiro; ARDIGO, Julíbio David. Da trajetória dos periódicos à implementação de indicadores de qualidade: análise das publicações periódicas científicas brasileiras das áreas de Ciência da Informação e Biblioteconomia. Revista $A C B$, [S.l.], v. 21, n. 3, p. 589606, dez. 2016. ISSN 1414-0594. Disponível em: https://revista.acbsc. org.br/racb/article/view/1200. Acesso em: 22 dez. 2020.

SOUZA, Saulo Aparecido de. O que é um tribunal de contas? Estudo sob a perspectiva popular, em Curitiba (PR). Cadernos Gestão Pública e Cidadania, [S.1.], v. 21, n. 70, p. 282-302, 5 dez. 2016. Fundação Getulio Vargas. http://dx.doi.org/10.12660/cgpc. v21n70.59404. Disponível em: http://bibliotecadigital.fgv.br/ojs/ index.php/cgpc/article/view/59404/63050. Acesso em: 15 out. 2019.

TRAN, Mai An; NGUYEN, Bang; MELEWAR, T.C.; BODOH, Jim. Exploring the corporate image formation process. Qualitative Market Research: An International Journal, [S.1.], v. 18, n. 1, p. 86-114, 12 jan. 2015. Emerald. http://dx.doi.org/10.1108/qmr05-2014-0046. Disponível em: https://www.emerald.com/insight/ content/doi/10.1108/QMR-05-2014-0046/full/html. Acesso em: 22 set. 2020 .

VIEIRA, Paulo Roberto da Costa; FREITAS, Jorge Augusto de Sá Brito e. Transparência e Imagem Institucional: o caso do banco central do brasil. Revista Eletrônica Gestão e Sociedade, [S.I.], v. 1, n. 1, p. 1-22, ago. 2007. Disponível em: https://www.gestaoesociedade. org/gestaoesociedade/article/view/545. Acesso em: 22 set. 2020.

ZANINI, Marco Tulio; MIGUELES, Carmen Pires; COLMERAUER, Marcio; MANSUR, Juliana. Os Elementos de 
Coordenação Informal em uma Unidade Policial de Operações Especiais. Revista de Administração Contemporânea, Rio de Janeiro, v. 17, n. 1, p. 106-125, fev. 2013. Disponível em: http://www.spell.org. $\mathrm{br} /$ documentos/ver/9097/os-elementos-de-coordenacao-informal-emuma-unidade-policial-de-operacoes-especiais. Acesso em: 15 out. 2019. 


\title{
INFORMAÇÕES ADICIONAIS E DECLARAÇÕES DOS AUTORES
}

\author{
(integridade cientifica)
}

Declaração de conflito de interesse: $\mathrm{O}(\mathrm{s})$ autor(es) confirma(m) não haver conflitos de interesse na condução desta pesquisa e na redação deste artigo.

Declaração de autoria: Todos e apenas os pesquisadores que atendem os requisitos de autoria deste artigo são listados como autores; todos os coautores são integralmente responsáveis por este trabalho em sua totalidade.

Declaração de originalidade: $\mathrm{O}(\mathrm{s})$ autor(es) assegura(m) que o texto aqui publicado não foi previamente divulgado em qualquer outro local e que a futura republicação apenas será feita com expressa referência desta publicação original; também atesta(m) que não há plágio de material de terceiros ou autoplágio.

\section{Como Citar (Abnt Brasil)}

COSTA, Vinicius Paulo da Silva Costa; SANTOS, Aline Regina; ARDIGO, Juliane Pierri. A influência da Operação Mãos Dadas na imagem institucional da Polícia Militar de Santa Catarina. Revista Brasileira de Ciências Policiais, vol. 13, n. 7, p. 263302, jan./abr. 2022.

https://doi.org.br/10.31412/rbcp.v13i7.826 